\title{
INTERVENCIÓN DEL TRIBUNAL DE JUSTICIA DE LA UNIÓN EUROPEA EN EL ÁMBITO DE COORDINACIÓN DE LOS SISTEMAS DE SEGURIDAD SOCIAL EUROPEOS
}

\author{
Intervention of the court of justice of the European Union in the \\ area of coordination of the european social security systems
}

\author{
Verónica Lidia Martínez Martínez \\ Doctora en Derecho ${ }^{1}$ \\ Profesora-Investigadora de la Universidad Anáhuac (México) \\ marb_cap@hotmail.com
}

http://dx.doi.org/10.18543/ed-68(2)-2020pp169-204

Recibido: 30.06 .2020

Aceptado: 21.12.2020

\section{Resumen}

Partiendo de una sucinta exposición de los antecedentes, integración y atribuciones del Tribunal de Justicia de la Unión Europea, con base en el método analítico y la consulta de los principales fallos pronunciados por este órgano jurisdiccional, en este trabajo son expuestas las principales temáticas de la jurisprudencia del Tribunal de Luxemburgo en el ámbito de la coordinación de los sistemas de Seguridad Social europeos.

\section{Palabras clave}

Seguridad social, coordinación, Tribunal de Justicia de la Unión Europea, jurisprudencia, principios.

${ }^{1}$ Doctora y maestra en derecho, especialista en derecho social y licenciada en derecho, título y grados obtenidos con Mención Honorífica. Investigadora Nacional del Sistema Nacional de Investigadores del Consejo Nacional de Ciencia y Tecnología. 


\section{Abstract}

Starting from a succinct exposition of the antecedents, integration and attributions of the Court of Justice of the European Union, based on the analytical method and the consultation of the main rulings pronounced by this jurisdictional body, in this work the main themes of the jurisprudence of the Luxembourg Court in the field of coordination of European Social Security systems.

\section{Keywords}

Social security, coordination, Court of Justice of the European Union, jurisprudence, principles. 


\begin{abstract}
SUMARIO: I. ORIGEN DEL TRIBUNAL DE JUSTICIA DE LA UNIÓN EUROPEA. II. INTEGRACIÓN Y ATRIBUCIONES DEL TRIBUNAL DE JUSTICIA DE LA UNIÓN EUROPEA. III. JURISPRUDENCIA EN MATERIA DEL SISTEMA DE COORDINACIÓN DE LA SEGURIDAD SOCIAL. 1. Creación normativa. 2. Incumplimiento a las obligaciones del derecho comunitario. 3. Principios básicos del sistema de coordinación en materia de seguridad social. 4. Determinación de la legislación aplicable. 5. Ámbito material y personal de los reglamentos de coordinación en materia de seguridad social. 6. Bases de cotización. IV. ConCLusión. V. FuENTES DE CONSULTA.
\end{abstract}

\title{
I. ORIGEN DEL TRIBUNAL DE JUSTICIA DE LA UNIÓN EUROPEA
}

Robert Schuman, ministro francés de Asuntos Exteriores, pronunció la Declaración que lleva su nombre el 9 de mayo de 1950. En ella propuso la creación de una Comunidad Europea del Carbón y del Acero (CECA) así como el establecimiento de un poder judicial. De acuerdo con el Tratado de París, firmado el 18 de abril de 1951, la nueva Comunidad estaría integrada por cuatro órganos primarios: una Alta Autoridad; una Asamblea Común, un Tribunal de Justicia y un Consejo de Ministros. ${ }^{2}$

El Tribunal de Justicia, integrado por siete jueces, ${ }^{3}$ nombrados de común acuerdo por los gobiernos de los Estados miembro de la CECA, de entre personalidades que ofrecían absolutas garantías de independencia y competencia, ${ }^{4}$ era el órgano facultado para controlar la legalidad de los actos y omisiones de la Alta autoridad, por lo que sus miembros podían ser cesados por el Tribunal de Justicia, a instancia de la Alta Autoridad o del Consejo Especial de Ministros, en los casos previstos por el Tratado Constitutivo de la Comunidad Europea del Carbón y del Acero, ${ }^{5}$ además de disponer de la facultad para anular, a petición de uno de los Estados miembro o de la Alta Autoridad, los acuerdos de la Asamblea o del Consejo. ${ }^{6}$

2 Artículo 7 Tratado Constitutivo de la Comunidad Europea del Carbón y del Acero, Disponible en: http://ocw.uc3m.es/historia-del-derecho/historia-de-la-integracion-europea/tratados/Tratado_Ceca.pdf/view. Fecha de consulta: 9 de junio de 2020.

${ }^{3}$ Los primeros jueces se nombraron en diciembre de 1952, y la primera sentencia lleva la fecha de 21 de diciembre de 1954. Asunto 1-54, República Francesa contra Alta Autoridad de la Comunidad Europea del Carbón y del Acero, [ECLI:EU:C:1954:7].

${ }^{4}$ Artículo 32 Tratado Constitutivo de la Comunidad Europea del Carbón y del Acero, op. cit.

5 Ibidem. Artículo 12 del Tratado Constitutivo de la Comunidad Europea del Carbón y del Acero.

${ }^{6}$ Ibidem. Artículo 38 del Tratado Constitutivo de la Comunidad Europea del Carbón y del Acero. 
En suma el Tribunal de Justicia al erigirse como un órgano auténticamente jurisdiccional tenía en sus manos garantizar el respeto del derecho en la interpretación y aplicación del Tratado Constitutivo de la Comunidad Europea del Carbón y del Acero, así como de sus reglamentos de ejecución. $^{7}$

De manera paralela a la firma de los Tratados Constitutivos de la Comunidad Económica Europea (CEE) y de la Comunidad Europea de Energía Atómica (CEEA llamada Euratom) o Tratados de Roma, se firmó y entró en vigor un Convenio sobre Instituciones Comunes que creó al Tribunal de Justicia de las Comunidades Europeas (TJCE) para llevar a cabo la interpretación y aplicación de ambos tratados. A partir del 7 de octubre de 1958 en que tuvo lugar el nombramiento de los jueces y de la publicación del Reglamento de Procedimiento el 3 de marzo de 1959, el TJCE comenzó a funcionar en Luxemburgo.

En 1999, como resultado de la firma del Tratado de Ámsterdam, se ampliaron las competencias del Tribunal de Luxemburgo, al poder intervenir en la protección de de los derechos humanos como consecuencia de la aprobación e incorporación al Derecho de la Unión Europea de la Carta de Derechos Fundamentales de la Unión Europea, así como de la aprobación de diferentes Directivas destinadas a la protección de determinados derechos humanos como el derecho a la igualdad, la protección de datos de carácter personal, a la vida privada, por citar algunos ejemplos.

La jurisprudencia el Tribunal de Justicia reconoce la obligatoriedad de los derechos fundamentales como principios generales del Derecho sobre la base de un triple fundamento: los derechos fundamentales comprendidos dentro de los principios generales del derecho comunitario, ${ }^{8}$ las tradiciones constitucionales de los Estados miembro, toda vez que no pueden admitirse en la Comunidad medidas incompatibles con los derechos fundamentales reconocidos en los textos constitucionales de dichos Estados y por último, con los

${ }^{7}$ Ibidem. Artículo 31 Tratado Constitutivo de la Comunidad Europea del Carbón y del Acero.

8 Ya en 1969 en el caso Stauder, el Tribunal reconoció, al menos implícitamente, en un obiter dictum que los derechos fundamentales de la persona formaban parte de los principios generales del Derecho comunitario. Poco después, en el asunto Internationale Handelsgesellschaft, en el que el recurrente había alegado una violación de sus derechos fundamentales por parte de un acto comunitario, el Tribunal, si bien rechazó que tal violación se hubiese producido, reconoció expresamente que el respeto de los derechos fundamentales es parte integrante de los principios generales del derecho. Posteriormente, en el caso Nold el Tribunal de Justicia puntualizó su jurisprudencia haciendo referencia a los instrumentos nacionales a los que los Estados miembro se habían adherido o en cuya elaboración habían participado. En particular, se hacía referencia al Convenio Europeo para la Protección de los Derechos Humanos y Libertades Fundamentales. 
instrumentos jurídico-internacionales de los que son parte los Estados miembro en materia de derechos humanos, ${ }^{9}$ en particular, el Convenio Europeo para la Protección de los Derechos Humanos y de las Libertades Fundamentales (bloque de fundamentalidad).

El antiguo Tribunal de Justicia de las Comunidades Europeas (TJCE) que a partir del Tratado de Lisboa se denomina Tribunal de Justicia de la Unión Europea (en adelante TJUE) es la autoridad judicial de la Unión Europea. Ante la desaparición de la estructura de pilares introducida por el Tratado de Maastricht, el Tribunal de Luxemburgo en colaboración con los órganos jurisdiccionales de los Estados miembro vela por la aplicación e interpretación uniforme del Derecho de la Unión, es decir, controla la legalidad de los actos de las instituciones de la Unión Europea; vela por que los Estados miembro respeten las obligaciones establecidas en los Tratados e interpreta el Derecho de la Unión a solicitud de los jueces nacionales. De esta manera el TJUE funciona como un tipo de Tribunal Supremo al situarse sus decisiones a un nivel superior con respecto a las de los tribunales nacionales, ${ }^{10}$ incluidos los tribunales constitucionales.

\section{INTEGRACIÓN Y ATRIBUCIONES DEL TRIBUNAL DE JUSTICIA DE LA UNIÓN EUROPEA}

Con excepción de la necesidad de adaptarse a las variaciones del número de Estados miembro y al incremento de los asuntos que debe resolver, el Tribunal de Justicia es una de las instituciones que menos cambios ha experimentado a lo largo de su existencia. En la actualidad el Máximo Tribunal de la Unión se integra por dos órganos jurisdiccionales: el Tribunal de Justicia y el Tribunal General. El Tribunal de la Función Pública, creado en 2004, puso fin a sus actividades el $1^{\circ}$ de septiembre de 2016, al traspasar sus competencias al Tribunal General.

El Tribunal General está compuesto por dos jueces por cada Estado miembro. ${ }^{11}$ Los jueces son nombrados de común acuerdo por los gobiernos de los Estados miembro, previa consulta a un comité encargado de emitir un dictamen sobre la idoneidad de los candidatos. Su mandato es de seis años

9 Asunto 5/88, Hubert Wachauf en contra de Bundesamt für Ernährung und Forstwirtschaft. STJ 13 de julio de 1989. [ECLI:EU:C:1989:321].

${ }^{10}$ K. Alter, Establishing the Supremacy of the European Law, Oxford, Oxford University, Press, 2001.

${ }_{11}$ Artículo 48 del Estatuto del Tribunal de Justicia de la Unión Europea (versión consolidada), Disponible en: https://curia.europa.eu/jcms/upload/docs/application/ pdf/2016-08/tra-doc-es-div-c-0000-2016-201606984-05_01.pdf. Fecha de consulta: 2 de mayo de 2020 . 
con posibilidad de renovación. Los jueces designan al presidente y vicepresidente del Tribunal General que duran en su encargo tres años.

Los asuntos de que conoce el Tribunal General se sustancian en salas compuestas por tres o cinco jueces o, en determinados casos, en formación de juez único ante la ausencia de dificultad de las cuestiones de Derecho o de hecho suscitadas, la escasa importancia del asunto y la ausencia de otras circunstancias particulares. El Tribunal General también puede reunirse en Gran Sala (quince jueces), cuando las circunstancias particulares o la importancia del asunto lo justifiquen.

En primera instancia el Tribunal General resuelve los recursos directos interpuestos por personas físicas y jurídicas para obtener la anulación de actos de las instituciones, órganos u organismos de la Unión Europea de los que sean destinatarias o que les afecten directa e individualmente, pronunciarse respecto de los actos reglamentarios que les afecten directamente y que no incluyan medidas de ejecución, ${ }^{12}$ así como resolver los recursos interpuestos por estas mismas personas con objeto de que se constate la inacción de dichas instituciones, órganos u organismos. ${ }^{13}$

Asimismo, es competente para resolver los recursos formulados por los Estados miembro contra la Comisión Europea y los recursos dirigidos a obtener la reparación de los daños causados por las instituciones o por los órganos u organismos de la Unión Europea o sus agentes; ${ }^{14}$ ejercer en primera instancia la competencia para resolver cualquier litigio entre la Unión y sus agentes, ${ }^{15}$ además de conocer de los conflictos que versan sobre cláusulas compromisorias contenidas en un contrato de Derecho público o de Derecho privado celebrado por la UE o por su cuenta en los que se otorgue competencia expresa al Tribunal General ${ }^{16} \mathrm{y}$ de las medidas de defensa comercial (dumping).

Otras de las materias en las que es competente el Tribunal General son los recursos en el ámbito de la propiedad intelectual dirigidos contra la Oficina de Propiedad Intelectual de la Unión Europea (EUIPO) y contra la Oficina Comunitaria de Variedades Vegetales (OCVV), además de los recursos interpuestos para combatir las decisiones de la Agencia Europea de Sustancias y Mezclas Químicas.

12 Artículo 263 del Tratado de Funcionamiento de la Unión Europea (TFUE), Disponible en: https://www.boe.es//doue/2010/083/Z00047-00199.pdf, fecha de consulta: 24 de junio de 2020 .

13 Ibidem. Artículo 265 del TFUE

14 Ibidem. Artículo 268 TFUE

15 Artículo 50 Bis del Estatuto del Tribunal de Justicia de la Unión Europea (versión consolidada), op. cit.

${ }^{16}$ Artículo 272 TFUE, op. cit. 
Por su parte, el Tribunal de Justicia está compuesto de un juez de cada país miembro y once abogados generales que lo asisten. Los jueces y los abogados generales son designados, de común acuerdo, por los gobiernos de los Estados miembro, previa consulta a un comité encargado de emitir un dictamen sobre la idoneidad de los candidatos propuestos para el ejercicio de las funciones de que se trate. Su mandato es de tres años con posibilidad de renovación. Los jueces elegirán de entre ellos al presidente y vicepresidente del Tribunal de Justicia por un período de tres años.

El Tribunal de Justicia puede reunirse en Pleno, en Gran Sala (quince jueces) o en Salas. El Tribunal de Justicia actúa en Gran Sala cuando lo solicite un Estado miembro o una institución de la UE sea parte en el proceso. Se reúne en Pleno cuando determine la destitución del Defensor del Pueblo o declare el cese de un comisario europeo que haya incumplido sus obligaciones y cuando considere que un asunto reviste una importancia excepcional. El resto de los asuntos se examinan en salas integradas por tres o cinco jueces.

El Tribunal de Justicia ostenta el carácter de supremo intérprete y guardián de la legalidad en el espacio europeo al ser competente para interpretar y aplicar la legislación de la UE, así como de realizar el control judicial. Se reservan al Tribunal de Justicia los recursos directos interpuestos por una institución de la Unión contra otra institución, así como aquéllos que se presenten por un Estado miembro en contra del Parlamento Europeo y del Consejo, salvo los interpuestos contra esta última institución relacionados con las ayudas de Estado, el dumping o las competencias de ejecución.

De igual manera, el Tribunal de Justicia es competente para resolver los recursos de incumplimiento y doble incumplimiento, así como el recurso de casación limitado a las cuestiones de Derecho interpuesto para combatir la incompetencia del Tribunal General o sus resoluciones; pronunciarse respecto de los recursos de anulación presentados para impugnar las decisiones adoptadas por el Consejo por las que se establezcan medidas restrictivas frente a personas físicas o jurídicas, como por ejemplo, la congelación de activos en el marco de la lucha contra el terrorismo. ${ }^{17}$

No obstante, que el Tribunal de Justicia carece de competencia para examinar la validez o proporcionalidad de operaciones efectuadas por la policía $\mathrm{u}$ otros servicios con funciones coercitivas de un Estado miembro ${ }^{18} \mathrm{y}$ para pronunciarse sobre la política exterior y de seguridad común (PESC), ${ }^{19}$ le compete vigilar que se respete la delimitación entre la PESC y las demás

${ }^{17}$ Ibidem. Párrafo segundo del artículo 275 TFUE

18 Ibidem. Artículo 275 TFUE

19 En virtud del Título V del Tratado UE (artículo 24 TUE, apartado 1, párrafo segundo), el Tribunal de Justicia no es competente para pronunciarse sobre la política exterior y de seguridad común (PESC). 
competencias de la Unión ya que, en virtud del artículo $40 \mathrm{TUE},{ }^{20}$ la ejecución de la PESC no debe afectar al ejercicio de las competencias de la UE.

\section{III.JURISPRUDENCIA EN MATERIA DEL SISTEMA DE COORDINACIÓN DE LA SEGURIDAD SOCIAL}

La jurisprudencia emitida por el TJUE es una de las piezas claves del proceso de integración europea, además de tener una posición preeminente en el sistema constitucional de fuentes, no sólo porque marca las notas y directrices de la coordinación en el ámbito de la Seguridad Social, sino porque complementa los instrumentos de coordinación y provoca su modificación para garantizar la tutela de los derechos de Seguridad Social.

Los principales temas de los que se ha ocupado la jurisprudencia de la Corte de Luxemburgo son la aportación de conceptos, de los principios del sistema de coordinación en materia de Seguridad Social, la delimitación de los ámbitos material y personal de los reglamentos comunitarios en el ámbito de la Seguridad Social, del incumplimiento a las obligaciones comunitarias, la determinación de la normatividad aplicable ante el surgimiento de los conflictos normativos y de las bases de cotización, que de manera breve se analizan en este último apartado.

\section{Creación normativa}

A través de su jurisprudencia, el Tribunal de Justicia aporta y delimita conceptos fundamentales para la coordinación de los sistemas de Seguridad Social, además de fijar los efectos de las herramientas que posibilitan la misma. En la sentencia de 15 de octubre de 1991 (asunto C-302/90) el Tribunal de Luxemburgo aborda el concepto del trabajador fronterizo para determinar que esta condición no se pierde por encontrarse en situación de desempleo total. ${ }^{21}$ Por su parte, en la sentencia de 5 de diciembre de 2019 dictada en los asuntos acumulados C-398/18 y C-428/18, fijó el alcance y la forma de integrar el concepto legal de «pensión a percibir» como requisito para el acceso a la jubilación anticipada voluntaria. ${ }^{22}$ Ante su fundamentalidad, en diversos asuntos ${ }^{23}$ el Tribunal de Justicia se ha pronunciado respecto

${ }^{20}$ Idem. Artículo 275 TFUE

21 Asunto C-302/90, Caisse auxiliaire d'assurance maladie-invalidité (CAAMI) contra Napoleón y Jocelyne Faux, STJ 15 de octubre de 1991, [ECLI:EU:C:1991:385].

${ }^{22}$ Asunto acumulados C-398/18 y C-428/18, Antonio Bocero Torrico y Jörg Paul Konrad Fritz Bode contra Instituto Nacional de la Seguridad Social y Tesorería General de la Seguridad Social, STJ 5 de diciembre de 2019, [ECLI:EU:C:2019:1050].

${ }^{23}$ Asunto 249/83, Vera Hoeckx en contra de Openbaar Centrum voor Maatschappelijk Welzijn Kalmthout, STJ 27 de marzo de 1985, [ECLI:EU:C:1985:139]; Asunto 
del concepto de prestación de Seguridad Social para atribuir tal carácter al beneficio que se concede a sus beneficiarios al margen de cualquier apreciación individual y discrecional de sus necesidades personales, en función de una situación legalmente definida y en la medida en que la prestación se refiera a alguno de los riesgos enumerados en el artículo 3, apartado 1, del Reglamento 883/2004.

En la sentencia Depesme y otros, ${ }^{24}$ el Tribunal de Justicia se pronunció sobre el concepto de hijo de un trabajador, para determinar que bajo esta expresión, se incluye al hijo que tenga un vínculo de filiación con el trabajador y al hijo del cónyuge o de la pareja registrada por el operario, cuando éste último provea a la manutención del hijo, sin que sea necesario que determinen los motivos de dicha manutención, ni que calculen de forma precisa su cuantía.

En materia de desplazamiento de trabajadores en los asuntos acumulados C-359/16 y C-527/16, la Corte de Luxemburgo aporta la interpretación sobre del valor vinculante del certificado relativo a la legislación sobre Seguridad Social que se aplica al titular (E 101), que se convirtió en el certificado A 1. Conceptualizado el certificado A 1 como el formulario tipo elaborado por la Comisión Administrativa para la Seguridad Social de los Trabajadores Migrante $^{25}$ que se emite por la institución competente del país, cuya legislación sea aplicable (origen-empleo) y, a partir de su expedición certifica la condición de desplazado del trabajador y la continuidad de su aseguramiento en el país en el que labora normalmente siempre que, de conformidad con el artículo 12.1 del Reglamento 883/2004, la duración previsible de dicho trabajo no exceda de veinticuatro meses y de que dicha persona no sea enviada en sustitución de otra persona enviada.

En primer lugar, en la sentencia dictada en el caso Altun y otros (C-359/16), de 6 de febrero de 2018, ${ }^{26}$ el Tribunal de Justicia comenzó con una recapitulación de su jurisprudencia en la que se consigna que uno de los efectos más significativos de este formulario es que vincula a la institución competente y a los órganos jurisdiccionales del país de acogida, generando una presunción de conformidad a Derecho de la afiliación del trabajador al

C-433/13, Comisión contra República de Eslovaquia, STJ 16 de septiembre de 2015, [ECLI:EU:C:2015:602]; Asunto C-679/16, Procedimiento incoado por A, STJ 25 de julio de 2018, [ECLI:EU:C:2018:601]

24 Asuntos C- 401/15, C-402/15 y C-403/15, Noémie Depesme y otros contra Ministre de l'Enseignement supérieur et de la Recherche, STJ 15 de diciembre de 2016, [ECLI:EU:C:2016:955].

${ }_{25}$ Asunto C-620/15, A-Rosa Flussschiff GmbH contra Union de recouvrement des cotisations de sécurité sociale et d'allocations familiales d'Alsace (Urssaf) y Sozialversicherungsanstalt des Kantons Graubünden, STJ 27 de abril de 2017, [ECLI:EU:C:2017:309].

26 Asunto 359/16, Altun, STJ 6 de febrero de 2018, [ECLI:EU:C:2018:63]. 
sistema de Seguridad Social del Estado miembro de establecimiento de la empresa (Estado de empleo), por ello la regla general es que las autoridades de destino y sus órganos jurisdiccionales carecen de competencia para revocar los certificados emitidos. Empero, de acuerdo con la sentencia en comento, cuando existan pruebas de la obtención fraudulenta o abusiva de los certificados; se realicen las actuaciones judiciales pertinentes y de forma ineludible se agote el procedimiento de petición de revocación de oficio por el que se solicita la revisión a la autoridad expedidora y ésta no lo atiende con la debida diligencia, los tribunales nacionales del Estado de acogida tienen la posibilidad de no tener en cuenta el certificado A 1.

A lo anterior se adiciona que el 6 de septiembre de 2018, el Tribunal de Justicia dictó sentencia en el asunto Alpenrind y otros (C-527/16) ${ }^{27}$ para precisar los efectos de un certificado A 1. En la emisión de este fallo destacan tres aspectos. En primer lugar, el Tribunal de Justicia reiteró que los certificados A 1 expedidos por la institución competente de un Estado miembro (en este caso, Hungría) vinculan tanto a las instituciones de Seguridad Social como a los tribunales del Estado miembro en que se ejerza la actividad (en este caso, Austria) mientras no sean retirados o invalidados por el Estado miembro en el que se expidieron. Incluso los certificados conservan su validez aun cuando las autoridades competentes de los Estados miembro interesados acudan a la Comisión Administrativa de Coordinación de los Sistemas de Seguridad Social y este órgano determine que al haberse expedido de manera fraudulenta debían retirarse, toda vez que la función de dicha autoridad, al limitarse a conciliar las posturas de las autoridades competentes de los Estados miembro que acuden a ella, sus conclusiones tienen el valor jurídico de un dictamen.

En segundo lugar, el Tribunal de Justicia se remite a la sentencia de 30 de marzo de 2000, asunto C-178/97 Banks y otros, para determinar que los certificados A 1 pueden aplicarse de manera retroactiva aun cuando en la fecha de su expedición, la institución competente del Estado miembro en el que se desarrolle la actividad hubiera decidido que los trabajadores en cuestión debían someterse al seguro obligatorio de dicho Estado miembro.

Y, en tercer lugar, en términos del artículo 12.1 del Reglamento 883/2004 se establece la sujeción a la Seguridad Social del Estado de origen de los trabajadores desplazados, siempre que la duración del trabajo no exceda de veinticuatro meses y que dicha persona no sea enviada en sustitución de otra persona. En la sentencia en comento concluye el Tribunal de Justicia que de enviarse trabajadores a un mismo puesto de trabajo pero por empresas

27 Asunto C-527/16, Salzburger Gebietskrankenkasse y Bundesminister für Arbeit, Soziales und Konsumentenschutz contra Alpenrind GmbH y otros, STJ 6 de septiembre de 2018, [ECLI:EU:C:2018:669]. 
distintas, concurre un supuesto de sustitución. En consecuencia, cuando un trabajador desplazado por su empresario para efectuar un trabajo en otro Estado miembro sea sustituido por otro trabajador desplazado por otro empresario, no puede seguir estando sujeto a la legislación del Estado miembro en el que su empresario ejerce normalmente sus actividades, ya que por lo general, los trabajadores están sujetos al régimen de Seguridad Social del Estado miembro en el que trabajan para garantizar del modo más eficaz posible, la igualdad de trato de todas las personas que trabajen en el territorio de ese Estado miembro.

\section{Incumplimiento a las obligaciones del Derecho comunitario}

En el marco de los recursos por incumplimiento que derivan de las denuncias presentadas por la Comisión Europea en contra de los Estados miembro se encuentran diversos fallos, como la sentencia dictada el 14 de junio de 2016 en el asunto C-308/14 en donde la Comisión denunció al Reino Unido por incumplimiento del Reglamento $883 / 2004 .^{28}$ En el fallo en comento, el Tribunal de Justicia resolvió que el ordenamiento comunitario, no se opone a que el reconocimiento de prestaciones sociales a ciudadanos de la Unión se condicione, por el Estado competente y a que los mismos cumplan con el requisito de tener derecho de residencia legal en el Estado de acogida. Incluso la exigencia de la legislación británica de comprobar la residencia habitual en su territorio que no se requiere su cumplimentación por parte de los nacionales británicos, no contraviene el principio de igualdad de trato, como lo alegó la Comisión, pues se trata de una medida proporcional a la necesidad de salvaguardar las finanzas del Estado miembro de acogida.

Por su parte, en la sentencia de 28 de noviembre de 1991 (asunto C-198/90), ${ }^{29}$ la Comisión Europea denunció el incumplimiento de los Países Bajos a las obligaciones que debe cumplir en términos del Tratado de la Comunidad Económica Europea, al denegar las asignaciones familiares a los trabajadores en situación de jubilación anticipada que residen fuera del territorio nacional, sujetos a la legislación neerlandesa.

En contraposición a lo que sostiene la Comisión, para el Tribunal de Justicia la letra a) del apartado 2 del artículo 13, no es aplicable a los trabajadores en situación de jubilación anticipada porque su finalidad es resolver los conflictos de legislación que pueden plantearse cuando, durante un mismo

${ }_{28}$ Asunto 308/14, Comisión Europea contra Reino Unido, STJ 14 de junio de 2016, [ECLI:EU:C:2016:436].

${ }_{29}$ Asunto C-198/90, Comisión de las Comunidades Europeas contra Reino de los Países Bajos, STJ 28 de noviembre de 1991, [ECLI:EU:C:1991:454]. 
período, el lugar de residencia y el de empleo no se sitúan en el mismo Estado miembro, siendo imposible que se produzcan este tipo de controversias en relación con los trabajadores que cesaron voluntariamente toda actividad profesional. Por consiguiente, aunque es cierto que los trabajadores en situación de jubilación anticipada continúan estando asegurados con arreglo a la legislación neerlandesa, cuya aplicación al no resultar de la norma de conflictual, provoca que a los trabajadores que disfrutan de un régimen de jubilación anticipada les sea inaplicables los artículos 73 y 75 del Reglamento 1408/71 que invocó la Comisión.

Otros casos en los que se denuncia el incumplimiento a las obligaciones comunitarias son los siguientes:

a. Asunto C-307/89, Comisión de las Comunidades Europeas contra República Francesa, STJ 11 de junio de 1991, [ECLI:EU:C:1991:245], en la que se determinó que la República Francesa incumplió con las obligaciones consignadas en el apartado 1 del artículo 3 del Reglamento 1408/71, al someter a los nacionales de otros Estados miembro residentes en Francia y comprendidos en el ámbito de aplicación de dicho Reglamento al doble requisito consistente, por una parte, en la firma de convenios internacionales de reciprocidad y, por otra parte, en haber residido previamente en su territorio para la obtención del subsidio complementario previsto en los artículos L 815-2 y L 815-3 del nouveau code de la sécurité sociale francés.

b. Asunto 311/01, Comisión de las Comunidades Europeas vs Países Bajos, STJ 6 de noviembre de 2003, [ECLI:EU:C:2003:598]. El TJUE determinó que el Reino de los Países Bajos incumplió las obligaciones que le incumben en virtud de los artículos 69 y 71 del Reglamento 1408/71, en su versión modificada y actualizada por el Reglamento 2001/83, de 2 de junio de 1983, al negarles a los trabajadores fronterizos en paro total, la posibilidad de desplazarse a uno o varios Estados miembro con el fin de buscar en ellos un empleo, conservando su derecho a las prestaciones de desempleo, en las condiciones establecidas en el artículo 69 del mismo reglamento.

c. Asunto C-356/15, Comisión Europea contra Reino de Bélgica, STJ 11 de julio de 2018, [ECLI:EU:C:2018:555]. El Tribunal de Luxemburgo determinó que el Reino de Bélgica incumplió las obligaciones que debe cumplimentar al oponerse al principio de la afiliación de los trabajadores por cuenta ajena a un único régimen de Seguridad Social, además de contravenir el principio de seguridad jurídica, que exige, en particular, que las normas jurídicas sean claras, precisas y de efectos previsibles, en especial cuando puedan tener consecuencias desfavorables para los particulares o las empresas. 


\section{Principios básicos del sistema de coordinación en materia de Seguridad Social}

A pesar de la disimilitud de los fallos, los principios básicos del sistema de coordinación son empleados por la Corte de Luxemburgo como criterios interpretativos. Como una pieza clave del proceso de integración europea, el principio-valor de la igualdad se emplea en cuatro planos positivos en el ámbito de la Seguridad Social. El primer plano es respecto de la igualdad que debe imperar entre los hombres y las mujeres de los Estados miembro para abatir la brecha que en materia de pensiones existe. Como ejemplos representativos de este rubro se encuentran los siguientes fallos:

a. Asunto C-173/91, Comisión contra Bélgica, STJ 17 de febrero de 1993, [ECLI:EU:C:1993:64].

b. Asunto C-127/92, M. Enderby contra Frenchay Healtj Authority, STJ 27 de octubre de 1993, [ECLI:EU:C:1993:859].

c. Asunto C-132/92, Birds Eye Valls Ltd. contra F. M. Roberts, STJ 9 de noviembre de 1993, [ECLI:EU:C:1993:868].

d. Asunto C-110/91, M. Morino contra Collo Gmbh, STJ 14 de diciembre de 1993, [ECLI:EU:C:1993:926].

e. Asunto C-152/91, D. Neath contra Hugj Steeper Ltd., STJ22 de diciembre de 1993, [ECLI:EU:C:1993:949].

f. Asunto C-328/91, Secretary of State for Social Security contra E. Thomas y otros, STJ 30 de marzo de 1993, [ECLI:EU:C:1993:117].

g. Asunto C-154/92, R. Van Cant contra Rijksdienst Voor Pensioenen, STJ $1^{\circ}$ de julio de 1993, [ECLI:EU:C:1993:282].

h. Asunto C-337/91, A. M. Van Gemert-Derks contra Bestuut Van de Nieuwe, STJ 27 de octubre de 1993, [ECLI:EU:C:1993:856].

i. Asunto C-537/07, Evangelina Gómez-Limón Sánchez-Camacho contra Instituto Nacional de la Seguridad Social (INSS), Tesorería General de la Seguridad Social (TGSS) y Alcampo SA, STJ 16 de julio de 2009, [ECLI:EU:C:2009:462].

j. En el asunto C-124/99, Carl Borawitz en contra de Landesversicherungsanstalt Westfalen, STJ de 21 de septiembre de 2000, [ECLI:EU:C:2000:485].

k. Asunto C-385/11, Isabel Elbal Moreno contra Instituto Nacional de SeguridadSocial,STJ22denoviembrede2012,[ECLI:EU:C:2012:746].

El segundo plano es el de la igualdad que debe existir entre los ciudadanos de la UE y los nacionales de terceros Estados para que puedan acceder a las prestaciones de Seguridad Social. Aquí es posible ubicar a los siguientes casos: 
a. Asunto C-23/92, M. Grana-Novoa contra Landesversicherungsanstalt, STJ 2 de agosto de 1993, [ECLI:EU:C:1993:339], en donde el Tribunal de Luxemburgo determinó que un convenio bilateral de seguridad social suscrito entre un Estado miembro y un Estado tercero, aun incorporado con rango de ley al derecho interno de los contratantes, no es parte del ámbito comunitario de actuación, por lo que es inoperante el principio de igualdad de trato.

b. Asunto C-55/00, Elide Gottardo contra contra Istituto nazionale della previdenza sociale, STJ 15 de enero de 2002, [ECLI:EU:C:2002:16], En la sentencia pronunciada en este asunto, el Tribunal de Justicia consideró que conforme al principio fundamental de igualdad de trato obliga a los Estados miembro a conceder a los nacionales de los demás Estados miembro las mismas ventajas que aquellas de las que disfrutan sus propios nacionales en virtud de dicho convenio, a menos que pueda justificar objetivamente su denegación. Por ello, se deben computar los períodos de seguro cubiertos en un Estado tercero por un nacional de un segundo Estado miembro cuando, en las mismas condiciones de cotización, se reconozca el cómputo de dichos períodos cubiertos por sus propios nacionales. Es así como el caso Gottardo cambia la doctrina Grana-Novoa, pero es congruente con las sentencias recaídas en los asuntos Matteucci ${ }^{30}$ y Saint-Gobain. ${ }^{31}$

En el tercer plano se encuentra los fallos que a partir de la igualdad consigna el derecho de las parejas homosexuales a acceder a las prestaciones en materia de Seguridad Social. Ejemplo de lo anterior es el asunto C-267/06

${ }^{30}$ A propósito de un acuerdo cultural que reservaba la concesión de becas de estudio a los nacionales de los Estados partes en dicho acuerdo, el Tribunal de Luxemburgo en el caso Matteucci consideró que el artículo 7 del Reglamento 1612/68, en el que se consagra el principio de igualdad de trato, obliga a ambos Estados a extender las ayudas previstas en el acuerdo a los trabajadores comunitarios establecidos en su territorio. Asunto: 235/87, Annunziata Matteucci contra Communauté française de Belgique y Commissariat général aux relations internationales de la Communauté française de Bélgica, STJ 27 de septiembre de 1988, [ECLI:EU:C:1988:460].

31 En el asunto Saint-Gobain en torno a un convenio internacional bilateral celebrado entre un Estado miembro y un tercer Estado, para evitar la doble imposición, el Tribunal de Luxemburgo reiteró la obligación de cumplir las normas comunitarias que recae sobre los Estados miembro, aunque la fiscalidad directa sea competencia exclusiva de estos últimos, toda vez que «el principio del trato nacional impone al Estado miembro parte en dicho convenio conceder a los establecimientos permanentes de sociedades no residentes, en las mismas condiciones aplicables a las sociedades residentes, las ventajas previstas en el convenio.» Asunto 307/97, Compagnie de Saint-Gobain, Zweigniederlassung Deutschland, contra Finanzamt Aachen-Innenstadt, STJ 21 de septiembre de 1999. [ECLI:EU:C:1999: 438]. 
suscitado entre Tadao Maruko en contra de Versorgungsanstalt der deutschen Bühnen (caja de pensiones de los teatros alemanes, en lo sucesivo VddB). ${ }^{32} \mathrm{El}$ 8 de noviembre de 2001, el señor Maruko constituyó una pareja estable inscrita con un diseñador de vestuario de teatro, quien desde el 1 de septiembre de 1959 se hallaba afiliado al VddB y continuó cotizando voluntariamente a esta entidad durante los períodos en que la afiliación no era obligatoria.

A consecuencia del fallecimiento del compañero del señor Maruko a través del escrito interpuesto el 17 de febrero de 2005 se solicitó al VddB la pensión de viudez en concepto de prestación de supervivencia establecida por el régimen profesional de pensiones al que estaba afiliado su pareja. A través de la decisión de 28 de febrero de 2005 la VddB denegó la solicitud porque en sus estatutos no preveían tal prestación de supervivencia para los miembros de las parejas inscritas. Para el VddB, no existe ninguna obligación de carácter constitucional por la que se deba tratar de manera idéntica, desde el punto de vista del Derecho de la Seguridad Social o de las prestaciones de previsión, el matrimonio y la pareja inscrita que constituye una institución sui generis y un nuevo estado de las personas.

Al pronunciarse el Tribunal de Justicia sobre este asunto determinó que constituye un caso de discriminación, si el miembro superviviente de una pareja inscrita, al ocurrir el fallecimiento del otro miembro, no tiene derecho a percibir una pensión de supervivencia equivalente a la que se otorga a un cónyuge supérstite, cuando, en el Derecho alemán, la institución de la pareja inscrita coloca a las personas del mismo sexo en una situación comparable a la de los cónyuges en lo relativo a dicha prestación de supervivencia. Empero, corresponde al órgano jurisdiccional remitente comprobar si el miembro superviviente de una pareja inscrita se halla en una situación comparable a la de un cónyuge beneficiario de la prestación de supervivencia establecida en el régimen de previsión profesional gestionado por el VddB.

$\mathrm{Y}$, el cuarto plano lugar, se encuentra la aplicación del principio de igualdad de trato en el caso de los transexuales para acceder a las prestaciones de Seguridad Social, en donde las sentencias del Tribunal de Justicia dictadas a partir de 1996, reflejan un criterio más progresista e incluyente que la posición conservadora asumida por el Tribunal Europeo de Derechos Humanos al pronunciarse sobre estos temas. ${ }^{33} \mathrm{La}$ transexualidad ha tenido repercusión, principalmente en el reconocimiento de las prestaciones, como la jubilación

32 Asunto C-267/06, Tadao Maruko vs Versorgungsanstalt der deutschen Bühnen, STJ $1^{\circ}$ de abril de 2008, [ECLI:EU:C:2008:179].

${ }^{33}$ En el asunto C-13/94, P. Vs. S. y Cornwall County Council, STJ 30 de abril de 1996. [ECLI:EU:C:1996:170], el Tribual de Justicia condena la discriminación por razón de sexo que venían padeciendo los transexuales; frente a la posición más conservadora defendida por el TEDH en su Sentencia de 27 de septiembre de 1990, Cossey vs. Reino Unido, en la que reconoció al Reino Unido el margen de apreciación. 
en el asunto C-423/04 en donde un transexual, convertido en mujer, pidió en Reino Unido su pensión a los 60 años. En el caso de autos, la normativa británica establecía, para las mujeres nacidas antes del 6 de abril de 1950 y para los hombres nacidos antes del 6 de diciembre de 1953, distintas edades de jubilación: 60 años y 65 años, respectivamente. De acuerdo con lo anterior, la pensión se denegó por la Administración de la Seguridad Social británica al considerar que como hombre debería esperar hasta los 65 años, determinación que se consideró una discriminación por razón de sexo. ${ }^{34}$

Igualmente, el caso C-451/16, suscitado entre MB en contra de Secretary of State for Work and Pensions, ${ }^{35}$ el Tribunal de Justicia se pronunció respecto de la denegación de una pensión de jubilación a una persona nacida de sexo masculino, casada con una mujer, que se había sometido ulteriormente a una operación quirúrgica de cambio de sexo, por no disponer de un certificado de reconocimiento definitivo de su cambio de sexo, que únicamente podía obtenerse después de la anulación de su matrimonio, lo cual era contrario a su deseo de seguir casada. Al considerarse que el objeto de conceder la pensión era proteger el riesgo de la vejez al conferir a la persona de que se trate un derecho individual a una pensión de jubilación adquirido en función de las cotizaciones abonadas a lo largo de su carrera profesional, con independencia de su situación matrimonial y ante el objetivo invocado por el gobierno británico, de evitar en aquella época el matrimonio entre personas del mismo sexo, el Tribunal de Justicia concluyó que la normativa controvertida constituía una discriminación directa por razón de sexo y, por consiguiente era incompatible con la Directiva 79/7.

Otro principio que ha provocado la emisión de una vasta doctrina jurisprudencial por parte de la Corte de Luxemburgo, es el de asimilación que oscila entre fallos emitidos en su contra y en su favor. Dentro del primer tipo de sentencias se encuentran los casos Coonan ${ }^{36}$ y Vigier $^{37}$ en los que el Tribunal de Justicia determinó que, cuando una legislación nacional supedite la afiliación a un régimen de Seguridad Social o a una determinada rama del mismo al requisito de que el interesado haya estado previamente afiliado al régimen de Seguridad Social nacional, el Reglamento 1408/71 no obliga a los Estados miembros a asimilar los períodos de seguro cubiertos en otro Estado miembro a aquellos que previamente hubiesen sido cubiertos en el territorio nacional.

${ }^{34}$ Asunto C-423/04, Sarah Margaret Richards contra Secretary of State for Work and Pensions, STJ 27 de abril de 2006, [ECLI:EU:C:2006:256],

35 Asunto C-451/16, MB contra Secretary of State for Work and Pensions, STJ 26 de junio de 2018, [ECLI:EU:C:2018:492].

${ }^{36}$ Asunto 110/79, Coonan contra Insurance Officer, STJ 24 de abril de 1980, [ECLI:EU:C:1980:1445].

${ }^{37}$ Asunto 70/80, Vigier contra Bundesversicherungsanstalt für Angestellte, STJ 27 de enero de 1981, [ECLI:EU:C:1981:19]. 
Asimismo, en el caso D'Amico, el Tribunal de Justicia consideró que no contraviene el Derecho comunitario la exigencia, a efectos de la concesión de una jubilación anticipada, de que el interesado se encuentre únicamente a disposición de las Oficinas de Empleo del Estado miembro, sin que pueda ser sustituido este requisito por el registro o inscripción como desempleado en las Oficinas de otro Estado Miembro. ${ }^{38}$

En tanto que dentro de las sentencias en las que el Tribunal de Justicia se pronunció en favor de la asimilación se encuentran el caso Dumont de Chassart. A partir del análisis de los artículos 72 y 79, apartado 1, letra a), del Reglamento 1408/71, el Tribunal de Luxemburgo consideró que dichos dispositivos legales, no se oponen a que se tomen en consideración los períodos de seguro y de empleo cubiertos por el progenitor superviviente de un hijo de un trabajador fallecido en otro Estado miembro, por el contrario, exigen que se tengan en cuenta, cuando la normativa del Estado miembro competente establece que, no sólo el progenitor fallecido, sino también el progenitor supérstite tienen la condición de trabajadores y pueden causar un derecho a prestaciones de orfandad, sin importar el hecho de que el progenitor fallecido no pueda invocar ningún período de seguro o de empleo en el Estado miembro en el curso del período de referencia establecido por la normativa nacional para la adquisición de tal derecho. ${ }^{39}$

Por su parte, el Tribunal de Justicia en el asunto Larcher también se pronunció en favor del principio de asimilación y en armonía con el principio de igualdad de trato al considerar que para reconocer, en un Estado miembro, un tiempo parcial previo a la jubilación que se haya desarrollado de conformidad con la normativa de otro Estado miembro, ha de realizarse un análisis comparativo de los requisitos de aplicación de los regímenes de esos dos Estados miembros a fin de determinar, en cada caso, si las diferencias identificadas pueden comprometer la consecución de los objetivos legítimamente perseguidos por la normativa controvertida de ese primer Estado miembro. ${ }^{40}$

En los asuntos Liégeois ${ }^{41}$ y Troiani ${ }^{42}$ por lo que hace al seguro facultativo continuado, el Tribunal de Justicia realizó una interpretación que se aleja del

${ }^{38}$ Asunto 20/75, Gaetano d'Amico contra Landesversicherungsanstalt RheinlandPfalz. STJ 9 de julio de 1975, [ECLI:EU:C:1975:891].

39 Asunto C-619/11, Patricia Dumont de Chassart vs. Office nationald'allocations familiales pour travailleurs salariés (ONAFTS), STJ 21 de febrero de 2013, [ECLI:EU:C:2013:92].

40 Asunto C-523/13, Walter Larcher vs. Deutsche Rentenversicherung Bayern Süd, STJ 18 de diciembre de 2014, [ECLI:EU:C:2014:2458].

${ }^{41}$ Asunto 93/76, Fernand Liégeois contra Office national des pensions pour travailleurs salarié, STJ 16 de marzo de 1977, [ECLI:EU:C:1977:50].

42 Asunto 368/87, Lieselotte Hartmann Troiani contra Landesversicherungsanstalt Rheinprovinz, STJ 18 de mayo de 1989, [ECLI:EU:C:1989:206]. 
sentido habitual del término, al decidir que engloba la asimilación de períodos de estudios a períodos de empleo, independientemente de la existencia de una relación de seguro establecida con anterioridad, además de cubrir el rescate retroactivo de derechos de pensión.

Dentro del marco normativo del Reglamento 883/2004, se encuentra el caso de los señores Knauer y Mathis, ${ }^{43}$ residentes en Austria que percibían una pensión de jubilación austriaca. Por su ejercicio profesional en Suiza y Liechtenstein, también se les otorgó pensiones de jubilación de la Caja de pensiones Hilti. A partir de 2010 se incorporó a la Ley General de Seguridad Social de Austria el artículo 73a, cuyo apartado 1 establece que el beneficiario de una pensión extranjera comprendida en el ámbito de aplicación del Reglamento 883/2004, si tiene derecho a percibir prestaciones del seguro de enfermedad, deberá abonar una cotización al régimen del seguro de enfermedad por dicha pensión extranjera.

Inconformes Knauer y Mathis con la aplicación de la disposición adoptada, el caso es sometido a la decisión del Tribunal Supremo de lo Contencioso-Administrativo de Austria, quien planteó la siguiente cuestión prejudicial: ¿Debe interpretarse el artículo 5 del Reglamento 883/2004, a la luz del artículo 45 TFUE, en el sentido de que constituyen "prestaciones equivalentes» a efectos de la mencionada disposición, las pensiones de jubilación abonadas por un régimen profesional de pensiones y las pensiones de jubilación abonadas por un régimen legal de pensiones?

El Tribunal de Justicia en la sentencia de 21 de enero de 2016 determinó que el concepto de prestaciones equivalentes debe interpretarse en el sentido de que se refiere a dos prestaciones de vejez que sean comparables. Para decretar la comparabilidad de las prestaciones, de acuerdo con la Corte de Luxemburgo, debió tenerse en cuenta el objetivo perseguido por las prestaciones y las normativas que las establecieron. En consecuencia, las prestaciones de vejez abonadas por el régimen profesional de pensiones de Liechtenstein y las abonadas por el régimen legal de pensiones austriaco al perseguir un mismo objetivo, esto es, permitir que sus beneficiarios mantengan un nivel de vida acorde con el nivel de que disfrutaban antes de su jubilación son prestaciones comparables, a pesar de que existan diferencias entre ellas, como el modo de adquisición del derecho a percibir dichas prestaciones o la posibilidad de que los asegurados disfruten de prestaciones complementarias facultativas. Como puede advertirse, del caso Knauer se desprende como criterio para la aplicación del principio de asimilación, que es necesario que las prestaciones respondan a los mismos o similares objetivos y las

${ }^{43}$ Asunto 453/14, Vorarlberger Gebietskrankenkasse y Alfred Knauer contra Landeshauptmann von Vorarlberg, STJ 21 de enero de 2016, [ECLI:EU:C:2016:37]. 
diferencias que no tienen una influencia decisiva en el objetivo perseguido resultan irrelevantes.

Respecto del principio de exportación existe pronunciamiento del Tribunal de Justicia en la sentencia de 21 de marzo de 2018, asunto C-551/16, suscitado entre J. Klein Schiphorst y Raad van bestuur van het Uitvoeringsinstituut werknemersverzekeringen, ${ }^{44}$ en donde debía determinarse si el periodo de prórroga de hasta tres meses adicionales fijado en el artículo 64.3 del Reglamento 883/2004 constituye o no una obligación para los Estados miembro.

El señor Klein Schiphorst, nacional neerlandés, residente en los Países Bajos, percibía una prestación por desempleo con arreglo a la regulación neerlandesa. A poco más de un año de disfrute de su prestación de desempleo en el país de residencia, el señor Klein comunicó a la entidad competente su intención de desplazarse a Suiza para buscar empleo, solicitando la exportación de su prestación de desempleo. A pesar de que su petición de exportación fue admitida, el señor Klein solicitó prorrogar la exportación de su prestación de desempleo a más de tres meses iniciales. Esta segunda solicitud al ser denegada fue recurrida hasta llegar el caso al Tribunal Central de Apelación, quien planteó la siguiente cuestión prejudicial: ¿sería conforme con el Derecho de la UE utilizar la facultad concedida en el artículo 64.1.c) del Reglamento 883/2004 de tal manera que, en principio, se deniegue toda solicitud de prórroga salvo que la institución en cuestión, según las circunstancias del caso, no pueda razonablemente denegarla (por ejemplo, si existieran perspectivas concretas y demostrables de conseguir empleo en el Estado de destino).

La determinación que adoptó el Tribunal de Justicia es que el artículo 64.1.c) del Reglamento 883/2004, no se opone a una medida nacional como la neerlandesa, pues dicho precepto recoge una posibilidad de prórroga, y no una obligación. Por tanto, las normas de coordinación permiten que una legislación nacional obligue a la institución competente a denegar toda solicitud de prórroga, con carácter general, salvo que ésta aprecie que dicha denegación no daría lugar a un resultado razonable.

\section{Determinación de la legislación aplicable}

Son numerosos los fallos de la Corte de Luxemburgo en los que se determinan las normas de Seguridad Social aplicables ante el ejercicio del derecho de circulación de los trabajadores, sobre todo en el caso de los trabajadores migrantes que al prestar sus servicios en el territorio de distintos países, por

${ }_{44}$ Asunto C-551/16, J. Klein Schiphorst contra Raad van bestuur van het Uitvoeringsinstituut werknemersverzekeringen, STJ 21 de marzo de 2018, [ECLI:EU:C:2018:200]. 
lo general, están o han estado sujetos a diferentes sistemas de Seguridad Social. Así, en el asunto 733/79, Caisse de compensation des allocations familiales des régions de Charleroi et de Namur en contra de Cosimo Laterza, ${ }^{45}$ el Tribunal de Justicia consideró que al no haberse establecido en favor de los trabajadores migrantes un esquema común en materia de Seguridad Social, sino que se posibilita la existencia de diferentes esquemas, ello da lugar a diferentes demandas en diferentes instituciones contra las que el demandante posee derechos directos, en virtud ya sea de Derecho nacional complementado, en su caso, por el derecho comunitario en el que se establecen las normas y el desarrollo de la coordinación de las normas nacionales sobre la regulación del Reglamento 1408/71, bajo el principio fundamental establecido en el séptimo y octavo considerandos de la exposición de motivos del mismo reglamento, que dispone que las normas debe garantizar a los trabajadores que se desplazan dentro de la Comunidad todos los beneficios que les han devengado en los distintos Estados miembro.

$\mathrm{Y}$ es que el carácter territorial de los sistemas estatales de Seguridad Social y las nuevas tendencias hacia la extensión extraterritorial de las normas nacionales de Seguridad Social genera diversos conflictos normativos que requieren de la interpretación del Máximo Tribunal de la Unión, como aconteció en el asunto C-631/17 suscitado entre SF y el Inspector de la Administración Tributaria en Países Bajos, ${ }^{46}$ en donde determinó que el artículo 11, apartado 3, letra e), del Reglamento 883/2004, en su versión modificada por el Reglamento 465/2012, de 22 de mayo de 2012, debió interpretarse en el sentido de que una persona, pese a trabajar como marinero por cuenta de un empresario con domicilio en un Estado miembro, en un buque que enarbola pabellón de un tercer Estado y que navega fuera del territorio de la Unión, conserva su residencia en su Estado miembro de origen, por lo tanto, la legislación nacional aplicable es la del Estado miembro de residencia de esa persona.

Por su parte, en el procedimiento incoado en el asunto C-302/02, el padre de Nils Laurin Effing ${ }^{47}$ fue trasladado a su país de origen, Alemania, para cumplir el resto de la condena decretada en su contra. Ante esta situación se decretó la suspensión del pago de las prestaciones familiares, pues conforme a la legislación austríaca el derecho a esta prestación se halla supeditado al requisito de que la persona de que se trate cumpla su pena en el territorio austriaco. De acuerdo con las circunstancias del asunto principal, y con

${ }^{45}$ Asunto 733/79, Caisse de compensation des allocations familiales des régions de Charleroi et de Namurvs. Cosimo Laterza, STJ 12 de junio de 1980, [ECLI:EU:C:1980:156].

46 Asunto C-631/17, SF en contra de Inspecteur van de Belastingdienst, STJ 8 de mayo de 2019, [ECLI:EU:C:2019:381].

${ }^{47}$ Asunto C302/02, Laurin Effing, STJ 20 de enero de 2005, [ECLI:EU:C:2005:36]. 
fundamento en lo dispuesto en el artículo 13, apartado 2, del Reglamento 1408/71, en su versión modificada por el Reglamento 1386/2001, de 5 de junio de 2001, el Tribunal de Luxemburgo al pronunciarse sobre la cuestión prejudicial determinó que la legislación aplicable en el ámbito de las prestaciones familiares era la legislación alemana.

En igual tenor, se encuentra el caso C-570/15, ${ }^{48}$ en donde el señor $\mathrm{X}$ es un nacional neerlandés que, durante el año 2009, residió en Bélgica, pero durante ese año, trabajó como gerente de cuentas y relaciones para un empresario establecido en los Países Bajos. Las horas laboradas eran un total de 1,872 , de las cuales trabajó 121 horas en Bélgica, lo que aproximadamente equivale a un $6,5 \%$ del total de horas de trabajo, distribuidas de la manera siguiente: 17 horas dedicadas a visitar a clientes del empresario establecidos en Bélgica y 104 horas en las que trabajó desde su casa en Bélgica. El resto de las horas $(1,751)$ el señor X trabajó en los Países Bajos. La controversia entre el señor X y el Staatssecretaris van Financiën, en lo general, versó sobre la determinación de la legislación aplicable de conformidad con el Reglamento 1408/71 en el caso de un trabajador residente en Bélgica que ejerce la mayor parte de su actividad para su empresario neerlandés en los Países Bajos, y en lo particular, el objeto del litigio consistió en determinar si X estaba sujeto al seguro obligatorio de la institución neerlandesa y, por ello, se encontraba obligado a pagar cotizaciones a la Seguridad Social a esta última institución.

Con base en la sentencia Format Urządzenia i Montaże Przemysłowe, ${ }^{49}$ después de tenerse en cuenta el volumen y la importancia de la actividad concreta, sobre la base de los documentos contractuales y de la realidad de las actividades ejercidas por el trabajador, el Tribunal de Justicia determinó que el Reglamento 1408/71, en su versión modificada y actualizada por el Reglamento 118/97 del Consejo, de 2 de diciembre de 1996, ha de interpretarse en el sentido de que una persona que ejerce una actividad por cuenta ajena en un Estado miembro y reside en otro, y que durante el año 2009, desempeñó una pequeña parte de su actividad para el mismo empresario (aproximadamente, el 6,5\% de su tiempo de trabajo) en el segundo Estado miembro, principalmente trabajando desde casa, ejerce una actividad por cuenta ajena exclusivamente en el primer Estado miembro. Para el Tribunal de Justicia una persona que, en el marco de sucesivos contratos de trabajo en los que se especifica como lugar de trabajo el territorio de varios Estados miembro, únicamente trabaja, de hecho, durante cada uno de esos contratos, en el territorio

${ }^{48}$ Asunto C-570/15, X vs Staatssecretaris van Financiën (Secretario de Estado de Hacienda, Países Bajos), STJ 13 de septiembre de 2017, [ECLI:EU:C:2017:674].

49 Asunto C-115/11, Format Urządzenia i Montaże Przemysłowe sp. z o.o. contra Zakład Ubezpieczeń Społecznych, STJ 4 de octubre de 2012, [ECLI:EU:C:2012:606]. 
de uno sólo de esos Estados a la vez, sin que pueda estar comprendida en el concepto de persona que ejerza normalmente una actividad por cuenta ajena en el territorio de dos o más Estados miembro.

En el asunto Natalino Ventura contra Landesversicherungsanstalt Schwaben, ${ }^{50} \mathrm{el}$ litigio tiene lugar entre el hijo de un trabajador migrante, fallecido el 30 de agosto de 1974 en la República Federal de Alemania, y el Landesversicherungsanstalt Schwaben (en lo sucesivo LVA Schwaben), que se negó a continuar abonando la pensión íntegra de orfandad cuando en el mes de julio de 1975 fijó su residencia en Italia. El LVA Schwaben basó su decisión en el inciso i) de la letra b) del apartado 2 del artículo 78 del Reglamento 1408/71 que dispone que cuando el asegurado fallecido ha estado sujeto a las legislaciones de varios Estados miembro, la obligación de abonar las prestaciones de orfandad incumbe a las autoridades competentes del Estado de residencia del interesado.

Sin embargo, las autoridades italianas se negaron a abonar la pensión de que se trata, con base en el apartado 1 del artículo 48 del Reglamento 1408/71 que ordena que la institución competente de un Estado miembro, no está obligada a conceder prestaciones cuando la duración total de los períodos de seguro o de residencia cubiertos bajo la legislación de dicho Estado miembro no llegue a ser de un año y cuando el cómputo exclusivo de esos únicos períodos no baste para conferir derecho a las prestaciones en el marco de dicha legislación.

Al considerar que esta negativa provocaría a las autoridades alemanas la obligación de abonarle desde 1975 el pago íntegro de la pensión de orfandad, Natalino Ventura interpuso una demanda ante el Sozialgericht de Augsburgo, solicitando la anulación de la resolución del LVA Schwaben, adoptada en 1975, y posteriormente interpuso recurso de apelación ante el Bayerische Landessozialgericht, quien decidió plantear la cuestión prejudicial siguiente: ¿ha de interpretarse el apartado 3 del artículo 44 del Reglamento 1408/71 del Consejo, de 14 de junio de 1971, en el sentido de que las prestaciones en favor de los huérfanos conforme a lo dispuesto en el artículo 79 del mismo Reglamento han de otorgarse a un huérfano residente en Italia sin aplicar el apartado 1 del artículo 48 del Reglamento, pero ha cubierto el período de carencia y cumple los requisitos internos de Italia para tener derecho a percibir prestaciones, aunque de forma conjunta con los períodos cubiertos en los demás Estados miembro?

En respuesta a la cuestión prejudicial planteada, el Tribunal de Justicia consideró que el artículo 44.3 del Reglamento 1408/71 debe interpretarse en el sentido de que las pensiones de orfandad deben regirse por las

50 Asunto C-269/87, Natalino Ventura vs Landesversicherungsanstalt Schwaben, STJ 14 de diciembre de 1988, [ECLI:EU:C:1988:545]. 
disposiciones del capítulo 8 de este ordenamiento completado por otras previsiones contenidas en el mismo, cuando fuera necesario y existiera expresa remisión. Esto va a suponer no aplicar a las prestaciones de orfandad las disposiciones del artículo 48.1 del Reglamento 1408/71 que prevén que, bajo ciertas condiciones, la institución competente de un Estado miembro, cuando los períodos de asegurado o residencia son inferiores a un año, no debe otorgar prestaciones por ese período.

\section{5. Ámbito material y personal de los reglamentos de coordinación}

La protección social extraterritorial se proyecta sobre un doble plano, el material u objetivo, donde se determina el alcance de la protección dispensada en función de la contingencia de que se trate; y el ámbito subjetivo, relativo a las personas, trabajadores o no, que van a ser los destinatarios de las diferentes fórmulas de protección diseñadas. ${ }^{51}$ Dentro de las sentencias en las que existe delimitación del contenido de las ramas de la Seguridad Social que constituyen el ámbito material de los reglamentos comunitarios en el ámbito de la Seguridad Social, la Corte de Luxemburgo parte de la distinción entre prestaciones excluidas del ámbito de aplicación del Reglamento 883/2004 y prestaciones incluidas a partir de los elementos constitutivos de cada prestación, principalmente en su finalidad y en los requisitos para obtenerla, y no en que una prestación sea o no calificada como prestación de Seguridad Social por una legislación nacional. ${ }^{52}$

De acuerdo con la anterior línea de interpretación, en la sentencia pronunciada el 12 de marzo de 2020, en el caso Caisse d'assurance retraite et de la santé au travail d'Alsace-Moselle en contra de SJ and Ministre chargé de la Sécurité sociale, asunto C-769/18,53 el Máximo Tribunal de la Unión deter-

${ }^{51}$ Correa Carrasco, Manuel. «El contrato de trabajo internacional y la protección social extraterritorial: problemas y soluciones», en Correa Carrasco, Manuel (coord.), La protección social en las relaciones laborales extraterritoriales, Ed. Ministerio de Trabajo y Asuntos Sociales, España, 2006, p. 56.

${ }_{52}$ Vid. Asunto 122/84, Kenneth Scrivner and Carol Cole contra Centre public d'aide sociale de Chastre, STJ 27 de marzo de 1985, [ECLI:EU:C:1985:145]. Asunto C-25/95, Siegfried Otte contra Bundesrepublik Deutschland, STJ 11 de julio de 1996, [ECLI:EU:C:1996:295]. Asunto C-160/96, Molenaar contra Allgemeine Ortskrankenkasse Baden-Württemberg, STJ 5 de marzo de 1998, [ECLI:EU:C:1998:84]. Asunto C-433/13, Comisión contra República de Eslovaquia, STJ 16 de septiembre de 2015, [ECLI:EU:C:2015:602]. Asunto C-679/16, A (Asistencia a persona con discapacidad), STJ 25 de julio de 2018, [ECLI:EU:C:2018:601].

${ }_{53}$ Asunto 769/18, Caisse d'assurance retraite et de la santé au travail d'Alsace-Moselle contra SJ y Ministre chargé de la Sécurité sociale, STJ 12 de marzo de 2020, [ECLI:EU:C:2020:203]. 
minó que la prestación por crianza de un hijo con discapacidad y la ayuda a la integración de niños y adolescentes con discapacidad mental, no son prestaciones equivalentes para efectos de la letra a) del artículo 5 del Reglamento 883/2004; mientras que en el caso C-356/8954resolvió que el subsidio de movilidad previsto en el Reino Unido debe tratarse como una prestación de invalidez en términos del Reglamento 1408/71.

Por el contrario, en la sentencia dictada el 18 de diciembre de 2019, en el asunto C-447/18, UB contra Generálny riaditel' Sociálnej poist'ovne Bratislava, ${ }^{55}$ el Tribunal de Justicia determinó que una prestación abonada a determinados deportistas de alto nivel que han representado a un Estado miembro o a sus predecesores legales, en competiciones deportivas internacionales, no está comprendida en el concepto de prestación de vejez en el sentido de dicha disposición y, por lo tanto, queda excluida del ámbito de aplicación material del Reglamento 883/2004.

Asimismo, en el caso 679/16 interpuesto por A para solicitar ante el Departamento de Prestaciones del Área de Asuntos Sociales y de Salud del municipio de Espoo, Finlandia; ${ }^{56}$ una prestación de asistencia personal en Tallin, Estonia, donde A cursa un ciclo de estudios de Derecho de tres años a tiempo completo, en la sentencia emitida el 25 de julio de 2018 el Tribunal de Luxemburgo determinó que la asistencia personal consistente en el abono de los gastos generados por las actividades cotidianas de una persona gravemente discapacitada que no realiza ninguna actividad económica, con el fin de que pueda cursar estudios superiores, no tiene cabida en el concepto de prestación de enfermedad y, por tanto, está excluida del ámbito de aplicación de Reglamento 883/2004.

En el caso Pensionsversicherungsanstalt contra CW, asunto C-135/19, ${ }^{57}$ el Tribunal de Justicia determinó, con base en el riesgo cubierto,${ }^{58}$ que el subsidio de rehabilitación constituye una prestación de enfermedad, en el sentido del artículo 3, apartado 1, letra a), del Reglamento 883/2004 en su versión modificada por el Reglamento 465/2012 de 22 de mayo de 2012. A pesar del anterior razonamiento, la prestación objeto del litigio se negó por-

${ }^{54}$ Asunto C-356/89, Roger Stanton Newton contra Chief Adjudication Officer STJ 20 de junio de 1991, [ECLI:EU:C:1991:265].

55 Asunto 447/18, UB contra Generálny riaditel' Sociálnej poist'ovne Bratislava. STJ 18 de diciembre de 2019, [ECLI:EU:C:2019:1098].

56 Asunto. 679/16, A contra Departamento de Prestaciones del Área de Asuntos Sociales y de Salud del municipio de Espoo, Finlandia, STJ 25 de julio de 2018 , [ECLI:EU:C:2018:601].

${ }_{57}$ Asunto C-135/19, Pensionsversicherungsanstalt contra CW, STJ 5 de marzo de 2020, [ECLI:EU:C:2020:177].

58 Asunto C-517/16, Stefan Czerwiński contra Zakład Ubezpieczeń Społecznych Oddział w Gdańsku.. STJ 30 de mayo de 2018, [ECLI:EU:C:2018:350]. 
que la interesada, no se rige por la legislación austríaca (Estado de origen), sino por la normativa del Estado miembro en el que se encuentra su residencia (Alemania), en donde no existe una prestación comparable al subsidio de rehabilitación austriaco.

En la sentencia de 30 de mayo de 2018 dictada en el asunto C-517/16 entre Stefan Czerwiński y el Zakład Ubezpieczeń Społecznych Oddział w Gdańsku (Organismo de Seguridad Social, Caja de Gdansk, en Polonia, el Tribunal de Justicia determinó, en primer lugar, que la clasificación de una prestación social en alguna de las ramas de Seguridad Social enumeradas en el artículo 3 del Reglamento 883/2004, realizada por la autoridad nacional competente en la declaración realizada por el Estado miembro con arreglo al artículo 9, apartado 1, del mismo reglamento 883/2004, no tiene carácter definitivo, toda vez que la clasificación puede realizarla el órgano jurisdiccional nacional de que se trate, de manera autónoma y en función de los elementos constitutivos de la prestación social controvertida. En virtud de lo anterior, una pensión transitoria debe considerarse una prestación de vejez en el sentido del artículo 3, apartado 1, letra d), del Reglamento 883/2004. ${ }^{59}$

Por su parte, en el asunto C-333/13 suscitado entre Elisabeta Dano y Florin Dano contra Jobcenter Leipzig, ${ }^{60}$ una nacional rumana que no había entrado en Alemania para buscar trabajo, sino para solicitar las prestaciones del seguro básico para demandantes de empleo, la Gran Sala del Tribunal de Justicia señaló que las prestaciones especiales en metálico no contributivas están comprendidas en el concepto de prestaciones de asistencia social previstas en el Reglamento 883/2004 y en el artículo 24, apartado 2, de la Directiva 2004/38. Ambos ordenamientos, no se oponen a que la normativa nacional excluya a nacionales de otros Estados miembros de la percepción de determinadas prestaciones sociales.

De acuerdo con el Tribunal de Justicia, por lo que se refiere al acceso a las prestaciones sociales, un ciudadano de la Unión sólo puede reclamar la igualdad de trato respecto de los nacionales del Estado miembro de acogida, cuando su estancia en el territorio de dicho Estado cumple los requisitos establecidos en la Directiva 2004/38. Entre los requisitos aplicables a los ciudadanos de la Unión que no ejerzan una actividad económica, cuyo período de residencia en el Estado miembro de acogida es superior a tres meses, pero inferior a cinco años, figura la obligación de disponer para ellos y para los miembros de su familia de recursos suficientes. En consecuencia, un Estado miembro tiene la posibilidad de denegar las prestaciones sociales a ciudadanos de la Unión que no ejerzan una actividad económica y ejercen su libertad

59 Idem

${ }^{60}$ Asunto C-333/13, Elisabeta Dano y Florin Dano contra Jobcenter Leipzig, STJ 11 de noviembre de 2014, [ECLI:EU:C:2014:2358]. 
de circulación con el único objetivo de poder disfrutar de la ayuda social de otro Estado miembro cuando no disponen de recursos suficientes para optar al derecho de residencia. Sobre este particular, procede efectuar un examen concreto de la situación económica de cada interesado, sin tener en cuenta las prestaciones sociales solicitadas.

Bajo la línea de interpretación de la sentencia dictada en el asunto Dano, en el caso C-299/14, suscitado entre Vestische Arbeit Jobcenter Kreis Recklinghausen contra Jovanna García-Nieto y otros ${ }^{61}$ la Corte de Luxemburgo reitera que un Estado miembro puede excluir de la percepción de determinadas prestaciones sociales a los nacionales de otros Estados miembros durante los tres primeros meses de su residencia, sin que tal denegación presuponga un examen de la situación individual de la persona interesada.

En el caso W. Jordens Vosters, de Overpelt (Bélgica) contra Bestuur van de Bedrijfsvereniging voor de Leder-en Lederverwerkende Industrie, de Tilburg (Países Bajos), ${ }^{62}$ el Tribunal de Justicia consideró que la expresión «prestaciones de enfermedad y de maternidad», en el sentido de la letra a) del apartado 1 del artículo 4 y del Capítulo 1 del Título III del Reglamento 1408/71, debe entenderse en el sentido de que engloba las prestaciones previstas por una legislación en materia de invalidez y que tienen carácter de prestaciones en concepto de atenciones sanitarias de naturaleza médica o quirúrgica.

Por su parte, en la sentencia de 14 de marzo de 2019, asunto C-372/18, suscitado entre el ministre de l'Action et des Comptes publics (Ministro de Actuación y Contabilidad Pública en Francia y el matrimonio Dreyer, residentes fiscales franceses, afiliados al régimen de Seguridad Social suizo, ${ }^{63} \mathrm{el}$ Tribunal de Justicia determinó que la asignación personalizada de autonomía y la prestación compensatoria de discapacidad deben concederse al margen de cualquier apreciación individual de las necesidades personales del beneficiario, habida cuenta de que los recursos de éste último únicamente se toman en consideración a fin de calcular el importe efectivo de dichas prestaciones de acuerdo con criterios objetivos y legalmente definidos.

Respecto de las prestaciones familiares, en el asunto C-117/89, Klaus Jürgen Kracht en contra de Bundesanstalt für Arbeit, ${ }^{64} \mathrm{el}$ Tribunal de Justicia

${ }^{61}$ Asunto 299/14, Vestische Arbeit Jobcenter Kreis Recklinghausen contra Jovanna García-Nieto y otros, STJ 25 de febrero de 2016. [ECLI:EU:C:2016:114].

${ }_{62}$ Asunto 69/79, Caso W. Jordens Vosters, de Overpelt (Bélgica) contra de Bestuur van de Bedrijfsvereniging voor de Leder-en Lederverwerkende Industrie, de Tilburg (Países Bajos), STJ 10 de enero de 1980. [ECLI:EU:C:1980:7].

${ }_{63}$ Asunto C-372/18, Ministre de l'Action et des Comptes publics contra M. et Mme Raymond Dreyer, STJ 14 de marzo de 2019, [ECLI:EU:C:2019:206].

${ }_{64}$ Asunto C-117/89, Klaus Jürgen Kracht contra Bundesanstalt für Arbeit, STJ 4 de junio de 1990, [ECLI:EU:C:1990:279]. 
determinó que el derecho a este tipo de beneficios, no debe suspenderse cuando éstas ya no sean pagaderas en el Estado miembro, en cuyo territorio residan los miembros de la familia únicamente porque no se han solicitado o vuelto a solicitar. Mientras que en la sentencia dictada el 22 de febrero de 1990 la Corte de Luxemburgo declaró que cuando la legislación del Estado miembro que proporciona ciertas asignaciones familiares requiere, como condición para otorgar estos subsidios, que el miembro de la familia del trabajador sea puesto a disposición. Este requisito debe considerarse cumplimentado cuando el miembro de la familia está a disposición como desempleado de la agencia de empleo del Estado miembro donde reside. ${ }^{65}$

En el caso Bundesanstalt Fur Arbeit (Oficina Federal de Empleo) y Kurt Beeck, ${ }^{66}$ en donde un trabajador fronterizo de nacionalidad alemana que labora en su país, pero reside en Dinamarca con su dos hijos y esposa, quien es empleada en este país y recibe asignaciones familiares, la controversia versó sobre la negativa de cubrir la mitad de las indemnizaciones alemanas pagables en relación con su segundo hijo en términos del artículo 8 , apartado 2, de la Ley Federal alemana sobre indemnizaciones familiares que contempla el pago de la mitad del importe de la prestación prevista a un menor dependiente cuando el beneficio otorgado por otro Estado miembro no supere el $75 \%$ del subsidio familiar. Con fundamento en el artículo 73.1 del Reglamento 1408/71, el Tribunal de Justicia consideró que esta disposición crea en favor del trabajador sujeto a la legislación de un Estado miembro, un derecho para que los integrantes de su familia que residen en el territorio de otro Estado miembro puedan recibir las prestaciones familiares que se prevén por la legislación del primer Estado, como si residieran en su territorio. Para que este precepto sea aplicable, el Tribunal de Luxemburgo refiere que basta con que el trabajador realice su actividad asalariada en el territorio de un Estado miembro mientras que los miembros de su familia residen en otro Estado miembro.

En la sentencia de 7 de febrero de 2019, dictada en el caso C-322/17 suscitado entre Eugen Bogatu y el Minister for Social Protection (Ministro para la Protección Social en Irlanda), en lo relativo a la decisión por la que este organismo denegó el pago de prestaciones familiares, el Tribunal de Justicia determinó que para percibir este tipo de beneficios prestacionales en el Estado miembro competente, no se requiere que la persona ejerza una actividad por cuenta ajena en dicho Estado miembro, ni que la persona perciba una prestación en metálico por el hecho o como consecuencia de dicha actividad

${ }^{65}$ Asunto C-228/88, Giovanni Bronzino contra Kindergeldkasse, STJ 22 de febrero de 1990, [ECLI:EU:C:1990:85].

66 Asunto C-104/80, Beeck vs Bundesanstalt für Arbeit, STJ 19 de febrero de 1981, [ECLI:EU:C:1981:48]. 
En cuanto a la delimitación del ámbito de aplicación personal, en los casos 182/78, ${ }^{67} 82 / 86$ y 103/86, ${ }^{68}$ el Tribunal de Luxemburgo atribuyó el carácter de trabajador, a la persona que aunque no se ejerza actividad alguna, se encuentre afiliado a un régimen de Seguridad Social. Bajo esta luz el Reglamento 1408/71 es aplicable a las personas que continúan protegidas por un régimen nacional de Seguridad Social pero que se desplazan fuera de la $\mathrm{UE},{ }^{69}$ aunque no con carácter general, ${ }^{70}$ ya que es la sumisión a una legislación de Seguridad Social de un Estado miembro la que determina la aplicación de la disposición reglamentaria.

Por su parte, en la sentencia de 12 de octubre de 1978, asunto C-10/78, el Tribunal de Luxemburgo resolvió que la condición de nacional de uno de los Estados miembro debe situarse en la época en que se ejerció el trabajo, se pagaron las cotizaciones correspondientes a los períodos de afiliación y adquirieron los derechos correspondientes. ${ }^{71}$ Mientras que en la sentencia dictada el 20 de diciembre de 2017, en el asunto 442/16, Florea Gusa en contra del Ministro de Asuntos Sociales de Irlanda y otros, ${ }^{72}$ el Tribunal de Justicia determinó que el nacional de un Estado miembro que, después de haber residido legalmente y ejercido una actividad como trabajador por cuenta propia en otro Estado miembro alrededor de cuatro años, ha abandonado esa actividad como consecuencia de la falta de trabajo - debidamente acreditada - motivada por causas ajenas a su voluntad y se ha inscrito ante el servicio de empleo competente de este último Estado miembro con el fin de encontrar un trabajo conserva la condición de trabajador por cuenta propia.

Otra sentencia es la de Maxwell Middle Burgh de 4 de octubre de 1991, asunto $15 / 90,{ }^{73}$ el Tribunal de la unión determinó que un trabajador por cuenta propia que tenga derecho a un subsidio por desempleo al cesar en su

${ }^{67}$ Asunto 182/78, Bestuur van het Algemeen Ziekenfonds Drenthe-Platteland contra G. Pierik, STJ 31 de mayo de 1979, [ECLI:EU:C:1979:142].

${ }_{68}$ Asuntos acumulados 82/86 y 103/86, Giancarlo Laborero y Francesca Sabato contra Office de sécurité sociale d'outre-mer (OSSOM), STJ 9 de julio de 1987, [ECLI:EU:C:1987:356].

${ }_{69}$ Asunto 300/84, A. J. M. Van Roosmal contra Bestuur van de Bedrijfsvereniging voor de Gezondheid, Geestelijke en Maatschappelijke Belangen, STJ 23 de octubre de 1986, [ECLI:EU:C:1986:402].

70 Asunto 153/91, Camille Petit v Office national des pensions, STJ 22 de septiembre de 1992, [ECLI:EU:C:1992:354].

${ }_{71}$ Asunto 10/78, Tayeb Belbouab contra Bundesknappschaft, STJ 12 de octubre de 1978, [ECLI:EU:C:1978:181].

72 Asunto 442/16, Florea Gusa contra Minister for Social Protection y otros en contra del Ministro de Asuntos Sociales de Irlanda y otros, STJ 20 de diciembre de 2017, [ECLI:EU:C:2017:1004].

73 Asunto C-15/90, David Maxwell Middleburgh contra Chief Adjudication Officer, STJ 4 de octubre de 1991, [ECLI:EU:C:1991:377]. 
trabajo por causas ajenas a su voluntad, en virtud de las cotizaciones pagadas como trabajador por cuenta ajena o que se consideren ingresadas por dicho concepto, no es un trabajador por cuenta ajena a efectos del apartado 1 del artículo 73 del Reglamento 1408/71, en su versión modificada y actualizada por el Reglamento 1390/81, de 12 de mayo de 1981.

Y en el asunto C-33/18, el Tribunal de Justicia declaró que una persona que, en la fecha de aplicación del Reglamento 883/2004 ejercía una actividad por cuenta ajena en un Estado miembro y una actividad por cuenta propia en otro Estado miembro, estando por tanto sujeta de manera simultánea a las legislaciones aplicables en materia de Seguridad Social de esos dos Estados miembro, no debía para quedar sujeta a la legislación aplicable en virtud del Reglamento 883/2004, en su versión modificada por el Reglamento 988/2009, presentar una solicitud expresa en este sentido.

\section{Bases de cotización}

Ante los diversos conflictos suscitados, principalmente en España, respecto de las bases de cotización que deben servir para calcular la pensión de los trabajadores migrantes, el Tribunal de Justicia se ha pronunciado en diversos asuntos para ofrecer una interpretación que sea acorde con el Derecho de la Unión Europea. Así, en la sentencia de 12 de septiembre de 1996, en el caso Eduardo Lafuente Nieto contra Instituto Nacional de la Seguridad Social (en adelante INSS) y Tesorería General de la Seguridad Social (en lo sucesivo TGSS), C-251/94, la Corte de Luxemburgo determinó que la cuantificación de las prestaciones por invalidez se debe realizar en una base media de cotización, cuyo cálculo debe tomar el importe de las cotizaciones pagadas con arreglo a la legislación de que se trata. ${ }^{74}$

Asimismo, en la sentencia de 9 de octubre de 1997, Antonio Naranjo Arjona contra INSS, Francisco Vicente Mateos contra INSS y TGSS e INSS contra Laura García Lázaro, de 9 de octubre de 1997, asuntos acumulados C-31/96, C-32/96 y C-33/96, ${ }^{75}$ así como en Aristóteles Grajera Rodríguez contra INSS y TGSS,${ }^{76}$ de 17 de diciembre de 1998, asunto C-153/97,

${ }^{74}$ Asunto C-251/94, Eduardo Lafuente Nieto contra Instituto Nacional de la Seguridad Social (INSS) y Tesorería General de la Seguridad Social, STJ 12 de septiembre de 1996, [ECLI:EU:C:1996:319].

75 Asuntos acumulados C-31/96, C-32/96 y C-33/96, Antonio Naranjo Arjona contra Instituto Nacional de la Seguridad Social (INSS), Francisco Vicente Mateos contra Instituto Nacional de la Seguridad Social (INSS) y Tesorería General de la Seguridad Social (TGSS) e Instituto Nacional de la Seguridad Social (INSS) contra Laura García Lázaro, STJ 9 de octubre de 1997, [ECLI:EU:C:1997:475].

76 Asunto C-153/97, Aristóteles Grajera Rodríguez contra Instituto Nacional de la Seguridad Social (INSS) y Tesorería General de la Seguridad Social (TGSS), STJ 17 de 
se reitera la interpretación realizada en el caso Lafuente Nieto, siendo importante que de manera expresa en ambos fallos se consigne la validez de las normas comunitarias que no imponen un método particular de determinación de las bases de cotización ni un método de actualización de dichas bases o de la pensión correspondiente, sino que solo pretenden que la cuantía de pensión se corresponda con la que habría percibido el trabajador migrante de haber ejercido su actividad en las mismas circunstancias en el Estado miembro de que se trate, y cumpliendo al mismo tiempo la obligación de tener en cuenta sólo los períodos de seguro cubiertos con arreglo a la legislación de que se trate.

La Corte de Luxemburgo en los fallos en comento reitera que la valoración de la actualización de las bases remotas corresponde a los tribunales nacionales con la matización de la doctrina Rönfeldt-Thévenon, es decir, no excluye la aplicación de las normas de un Convenio bilateral celebrado con anterioridad a la entrada en vigor del Reglamento $1408 / / 71$, cuando se produzca un resultado más favorable para el interesado. Lo anterior obedece a que los migrantes no pueden ser privados de sus derechos nacionales en virtud de la normativa de coordinación, que por su naturaleza tuitiva, siempre debe sumar protección y nunca restar la conseguida autónomamente

En igual tenor, sobresale 2013 el asunto Salgado González (C-282/11), ${ }^{77}$ en la que el Tribunal de Justicia, no analiza la cuestión prejudicial bajo la óptica del Reglamento 883/2004 por considerarlo inaplicable, sino a la luz del objetivo fijado, de acuerdo con la doctrina contenida en la sentencia Belbouab, ${ }^{78}$ el caso es estudiado bajo la óptica de la libertad fundamental de circulación de trabajadores dentro del mercado común.

Como antecedentes del caso es conveniente referir que la señora Concepción Salgado González cotizó en España en el Régimen Especial de Trabajadores Autónomos de febrero de 1989 a marzo de 1999 y en Portugal de marzo de 2000 a diciembre de 2005, por lo que solicitó una pensión de jubilación en España, que le fue reconocida por el INSS con efectos a partir del $1^{\circ}$ de enero de 2006. Para el cálculo de la base reguladora el INSS dividió la suma de las cotizaciones en España entre 210 (quince años), computando como períodos de cotización « $0 »$, la diferencia entre lo cotizado y los quince años mínimos, pero al considerar que también debían integrarse en el cálculo de su pensión de jubilación las cuotas que cotizó en Portugal, la señora Salgado González solicitó la revisión de ese importe.

diciembre de 1998. [ECLI:EU:C:1998:615].

77 Asunto C-282/11, Concepción Salgado González contra Instituto Nacional de la Seguridad Social (INSS) y Tesorería General de la Seguridad Social (TGSS), STJ 21 de febrero de 2013, [ECLI:EU:C:2013:86].

${ }^{78}$ Caso Tayeb Belbouab contra Bundesknappschaft, op. cit. 
El órgano jurisdiccional español indicó que no alberga ninguna duda acerca de la imposibilidad de tomar en cuenta las cuotas pagadas en Portugal para calcular la pensión de jubilación que debe pagar España, pero preguntó al Tribunal de Justicia, si la normativa española, que no permite adaptar ni la duración del período de cotización ni el divisor utilizados para tener en cuenta el hecho de que el trabajador ejerció su derecho a la libre circulación, es conforme con el Derecho de la Unión.

La Corte de Luxemburgo en su sentencia dictada el 21 de febrero de 2013 determinó que la normativa española establece una desigualdad de trato entre trabajadores sedentarios y migrantes, que sería diferente si la legislación española contemplara mecanismos de adaptación del procedimiento de cálculo de la base reguladora de la pensión de jubilación que tuvieran en cuenta el ejercicio por parte del trabajador de su derecho a la libre circulación. Concretamente, el divisor podría adaptarse para reflejar el número de cuotas efectivamente satisfechas por el asegurado por las remuneraciones ordinarias y extraordinarias. En consecuencia, para el Tribunal de Justicia, el Derecho de la Unión se opone a una normativa nacional en virtud de la cual la base reguladora de la pensión de jubilación de un trabajador por cuenta propia, migrante o no, se calcula invariablemente a partir de las bases de cotización de ese trabajador en un período de referencia fijo anterior al pago de su última cuota en ese Estado, a las cuales se aplica un divisor fijo, sin que resulte posible adaptar ni la duración de este período ni este divisor con el fin de tomar en consideración el hecho de que el trabajador en cuestión ha ejercido su derecho a la libre circulación.

De igual manera, en el asunto C-2/17, suscitado entre el INSS y Jesús Crespo Rey, se aborda el cálculo de la pensión teórica española en materia de pensiones de jubilación. El señor Crespo Rey, trabajador español después de quince años de cotización al sistema español de Seguridad Social al ejercer su derecho a la libre circulación en la UE, cotizó durante trece años en Suiza (país al que se le aplican los reglamentos europeos de coordinación en materia de Seguridad Social), con una base de cotización superior a la base mínima española. Al concluir su aseguramiento en Suiza y regresar a España, Crespo Rey decidió el $1^{\circ}$ de diciembre de 2007 suscribir un Convenio especial para los emigrantes españoles con la Seguridad Social española, de conformidad con lo establecido en el artículo 15 de la Orden Ministerial TAS/2865. Este convenio se mantuvo en vigor durante siete años, cotizando con la base mínima de cotización española.

Con base en las cotizaciones realizadas, Crespo Rey solicitó su jubilación en el INSS, quien determinó una pensión de jubilación con una cuantía muy baja al tomar el importe de la base mínima de cotización Inconforme con el cálculo del importe de su jubilación, Crespo Rey recurrió el el Juzgado de lo Social $n^{\circ} 1$ de La Coruña, cuya sentencia fue recurrida por el INSS ante el 
Tribunal Superior de Justicia de Galicia, quien decidió plantear las siguientes cuestiones prejudiciales ante el Tribunal de Justicia: 1) ¿deben entenderse excluidas de la expresión «la base de cotización que más se les aproxime en el tiempo» las derivadas de la aplicación de una norma interna como la española que limita su importe a la base mínima de cotización, limitación que no opera en el caso de trabajadores sedentarios que suscriban un convenio especial?; y en caso de respuesta afirmativa, 2) ¿sería adecuado para reparar el perjuicio causado tomar las últimas cotizaciones reales españolas debidamente actualizadas y considerar el periodo cotizado al amparo del convenio especial como periodo neutro o un paréntesis?

El Tribunal de Justicia en la sentencia dictada el 28 de junio de 2018 declaró que las normas en materia de libre circulación se oponen a una normativa nacional como la española que obliga a los trabajadores migrantes que suscriben un convenio especial con la Seguridad Social de ese Estado miembro a cotizar por la base mínima de cotización, produciendo el efecto que tuvo lugar en el cálculo de la pensión teórica del señor Crespo Rey, cuando un trabajador sedentario que no hizo uso de su derecho a la libre circulación y que suscribe tal convenio puede cotizar con arreglo a una base de cotización superior a la base mínima. Asimismo, el Tribunal de la Unión reconoció que es competencia del órgano jurisdiccional nacional determinar cuáles son los medios más adecuados para conseguir la igualdad de trato entre los trabajadores migrantes y sedentarios, pero señaló que, a priori, podría ser una buena solución permitir a los migrantes cotizar de manera retroactiva con arreglo a bases de cotización superiores a las mínimas y, con base en ellas, solicitar su jubilación.

\section{IV.CONCLUSIÓN}

Del contenido de las sentencias del Máximo Tribunal de la UE, que en su mayoría dilucidan las consultas o cuestiones prejudiciales, se infiere que la coordinación no implica unificación ni armonización de los sistemas de Seguridad Social europeos, al tiempo que tampoco veda las competencias soberanas de los Estados para organizar dichos sistemas ${ }^{79}$ que subsisten con todas sus peculiaridades, pues responden a la tradición jurídica, desarrollo, economía, política social e intereses políticos de cada Estado.

La jurisprudencia es una valiosa herramienta que completa el entramado normativo que hace posible la coordinación de los sistemas de Seguridad Social europeos, sea en su modalidad de reglamento, directiva o decisión, como instrumentos de Derecho derivado de carácter vinculante (hard law), a

79 Asunto C-158/96, Raymond Kohll vs. Union des caisses de maladie, STJ 28 de abril de 1998, [ECLI:EU:C:1998:171]. Asunto C-120/95, Nicolas Decker vs. Caisse de maladie des employés prives, STJ 28 de abril de 1998, [ECLI:EU:C:1998:167]. 
la vez que posibilita desde el ámbito jurisdiccional la intervención comunitaria en el ámbito doméstico de la seguridad cuando aplica e interpreta de manera uniforme el Derecho de la Unión a solicitud de los jueces nacionales, al controlar la legalidad de los actos de las instituciones de la Unión Europea o cuando vela por el respeto de las obligaciones comunitarias establecidas en el Derecho primario y el Derecho secundario.

Por supuesto que en este esfuerzo hermenéutico y de control de la legalidad que realiza el Tribunal de Luxemburgo, la voluntad política, la colaboración de los poderes públicos de Estados miembros y la existencia de los mecanismos nacionales que permitan la realización y acatamiento de las sentencias supranacionales del órgano jurisdiccional de la Unión es necesaria y fundamental para garantizar la tutela del derecho humano a la Seguridad Social como pilar fundamental de la protección social dentro del espacio comunitario europeo.

\section{FUENTES DE CONSULTA}

Correa CARrasco, Manuel. «El contrato de trabajo internacional y la protección social extraterritorial: problemas y soluciones», en Correa Carrasco, Manuel (coord.), La protección social en las relaciones laborales extraterritoriales, Ed. Ministerio de Trabajo y Asuntos Sociales, España, 2006.

K. Alter, Establishing the Supremacy of the European Law, Oxford, Oxford University, Press, 2001.

Tratado Constitutivo de la Comunidad Europea del Carbón y del Acero, Disponible en: http://ocw.uc3m.es/historia-del-derecho/historia-de-la-integracion-europea/ tratados/Tratado_Ceca.pdf/view. Fecha de consulta: 9 de junio de 2020.

Tratado de Funcionamiento de la Unión Europea, Disponible en: https://www.boe. es//doue/2010/083/Z00047-00199.pdf, fecha de consulta: 24 de junio de 2020.

Estatuto del Tribunal de Justicia de la Unión Europea (versión consolidada), Disponible en: https://curia.europa.eu/jcms/upload/docs/application/pdf/2016-08/tradoc-es-div-c-0000-2016-201606984-05_01.pdf. Fecha de consulta: 2 de mayo de 2020.

Asunto 5/88, Hubert Wachauf en contra de Bundesamt für Ernährung und Forstwirtschaft. STJ 13 de julio de 1989. [ECLI:EU:C:1989:321].

Asunto C-302/90, Caisse auxiliaire d'assurance maladie-invalidité (CAAMI) contra Napoleón y Jocelyne Faux, STJ 15 de octubre de 1991, [ECLI:EU:C:1991:385].

Asunto acumulados C-398/18 y C-428/18, Antonio Bocero Torrico y Jörg Paul Konrad Fritz Bode contra Instituto Nacional de la Seguridad Social y Tesorería General de la Seguridad Social, STJ 5 de diciembre de 2019, [ECLI:EU:C:2019:1050].

Asunto 249/83, Vera Hoeckx en contra de Openbaar Centrum voor Maatschappelijk Welzijn Kalmthout, STJ 27 de marzo de 1985, [ECLI:EU:C:1985:139]; Asunto C-433/13, Comisión contra República de Eslovaquia, STJ 16 de septiembre de 2015, [ECLI:EU:C:2015:602]; Asunto C-679/16, Procedimiento incoado por A, STJ 25 de julio de 2018, [ECLI:EU:C:2018:601] 
Asuntos C- 401/15, C-402/15 y C-403/15, Noémie Depesme y otros contra Ministre de l'Enseignement supérieur et de la Recherche, STJ 15 de diciembre de 2016, [ECLI:EU:C:2016:955].

Asunto C-620/15, A-Rosa Flussschiff GmbH contra Union de recouvrement des cotisations de sécurité sociale et d'allocations familiales d'Alsace (Urssaf) y Sozialversicherungsanstalt des Kantons Graubünden, STJ 27 de abril de 2017, [ECLI:EU:C:2017:309].

Asunto 359/16, Altun, STJ 6 de febrero de 2018, [ECLI:EU:C:2018:63].

Asunto C-527/16, Salzburger Gebietskrankenkasse y Bundesminister für Arbeit, Soziales und Konsumentenschutz contra Alpenrind GmbH y otros, STJ 6 de septiembre de 2018, [ECLI:EU:C:2018:669].

Asunto 308/14, Comisión Europea contra Reino Unido, STJ 14 de junio de 2016, [ECLI:EU:C:2016:436].

Asunto C-198/90, Comisión de las Comunidades Europeas contra Reino de los Países Bajos, STJ 28 de noviembre de 1991, [ECLI:EU:C:1991:454].

Asunto: 235/87, Annunziata Matteucci contra Communauté française de Belgique y Commissariat général aux relations internationales de la Communauté française de Bélgica, STJ 27 de septiembre de 1988, [ECLI:EU:C:1988:460].

Asunto 307/97, Compagnie de Saint-Gobain, Zweigniederlassung Deutschland, contra Finanzamt Aachen-Innenstadt, STJ 21 de septiembre de 1999. [ECLI:EU:C:1999: 438].

Asunto C-267/06, Tadao Maruko vs Versorgungsanstalt der deutschen Bühnen, STJ $1^{\circ}$ de abril de 2008, [ECLI:EU:C:2008:179].

Asunto C-423/04, Sarah Margaret Richards contra Secretary of State for Work and Pensions, STJ 27 de abril de 2006, [ECLI:EU:C:2006:256],

Asunto C-451/16, MB contra Secretary of State for Work and Pensions, STJ 26 de junio de 2018, [ECLI:EU:C:2018:492].

Asunto 110/79, Coonan contra Insurance Officer, STJ 24 de abril de 1980, [ECLI:EU:C:1980:1445].

Asunto 70/80, Vigier contra Bundesversicherungsanstalt für Angestellte, STJ 27 de enero de 1981, [ECLI:EU:C:1981:19].

Asunto 20/75, Gaetano d'Amico contra Landesversicherungsanstalt RheinlandPfalz. STJ 9 de julio de 1975, [ECLI:EU:C:1975:891].

Asunto C-619/11, Patricia Dumont de Chassart vs. Office nationald'allocations familiales pour travailleurs salariés (ONAFTS), STJ 21 de febrero de 2013, [ECLI:EU:C:2013:92].

Asunto C-523/13, Walter Larcher vs. Deutsche Rentenversicherung Bayern Süd, STJ 18 de diciembre de 2014, [ECLI:EU:C:2014:2458].

Asunto 93/76, Fernand Liégeois contra Office national des pensions pour travailleurs salarié, STJ 16 de marzo de 1977, [ECLI:EU:C:1977:50].

Asunto 368/87, Lieselotte Hartmann Troiani contra Landesversicherungsanstalt Rheinprovinz, STJ 18 de mayo de 1989, [ECLI:EU:C:1989:206].

Asunto 453/14, Vorarlberger Gebietskrankenkasse y Alfred Knauer contra Landeshauptmann von Vorarlberg, STJ 21 de enero de 2016, [ECLI:EU:C:2016:37]. 
Asunto C-551/16, J. Klein Schiphorst contra Raad van bestuur van het Uitvoeringsinstituut werknemersverzekeringen, STJ 21 de marzo de 2018, [ECLI:EU:C:2018:200].

Asunto 733/79, Caisse de compensation des allocations familiales des régions de Charleroi et de Namur vs. Cosimo Laterza, STJ 12 de junio de 1980, [ECLI:EU:C:1980:156].

Asunto C-631/17, SF en contra de Inspecteur van de Belastingdienst, STJ 8 de mayo de 2019, [ECLI:EU:C:2019:381].

Asunto C302/02, Laurin Effing, STJ 20 de enero de 2005, [ECLI:EU:C:2005:36].

Asunto C-570/15, X vs Staatssecretaris van Financiën (Secretario de Estado de Hacienda, Países Bajos), STJ 13 de septiembre de 2017, [ECLI:EU:C:2017:674].

Asunto C-115/11, Format Urządzenia i Montaże Przemysłowe sp. z o.o. contra Zakład Ubezpieczeń Społecznych, STJ 4 de octubre de 2012, [ECLI:EU:C:2012:606].

Asunto C-269/87, Natalino Ventura vs Landesversicherungsanstalt Schwaben, STJ 14 de diciembre de 1988, [ECLI:EU:C:1988:545].

Asunto 769/18, Caisse d'assurance retraite et de la santé au travail d'Alsace-Moselle contra SJ y Ministre chargé de la Sécurité sociale, STJ 12 de marzo de 2020, [ECLI:EU:C:2020:203].

Asunto C-356/89, Roger Stanton Newton contra Chief Adjudication Officer STJ 20 de junio de 1991, [ECLI:EU:C:1991:265].

Asunto 447/18, UB contra Generálny riaditel' Sociálnej poist’ovne Bratislava. STJ 18 de diciembre de 2019, [ECLI:EU:C:2019:1098].

Asunto. 679/16, A contra Departamento de Prestaciones del Área de Asuntos Sociales y de Salud del municipio de Espoo, Finlandia, STJ 25 de julio de 2018, [ECLI:EU:C:2018:601].

Asunto C-135/19, Pensionsversicherungsanstalt contra CW, STJ 5 de marzo de 2020, [ECLI:EU:C:2020:177].

Asunto C-517/16, Stefan Czerwiński contra Zakład Ubezpieczeń Społecznych Oddział w Gdańsku.. STJ 30 de mayo de 2018, [ECLI:EU:C:2018:350].

Asunto C-333/13, Elisabeta Dano y Florin Dano contra Jobcenter Leipzig, STJ 11 de noviembre de 2014, [ECLI:EU:C:2014:2358].

Asunto 299/14, Vestische Arbeit Jobcenter Kreis Recklinghausen contra Jovanna García-Nieto y otros, STJ 25 de febrero de 2016. [ECLI:EU:C:2016:114].

Asunto 69/79, Caso W. Jordens Vosters, de Overpelt (Bélgica) contra de Bestuur van de Bedrijfsvereniging voor de Leder-en Lederverwerkende Industrie, de Tilburg (Países Bajos), STJ 10 de enero de 1980. [ECLI:EU:C:1980:7].

Asunto C-372/18, Ministre de l'Action et des Comptes publics contra M. et Mme Raymond Dreyer, STJ 14 de marzo de 2019, [ECLI:EU:C:2019:206].

Asunto C-117/89, Klaus Jürgen Kracht contra Bundesanstalt für Arbeit, STJ 4 de junio de 1990, [ECLI:EU:C:1990:279].

Asunto C-228/88, Giovanni Bronzino contra Kindergeldkasse, STJ 22 de febrero de 1990, [ECLI:EU:C:1990:85].

Asunto C-104/80, Beeck vs Bundesanstalt für Arbeit, STJ 19 de febrero de 1981, [ECLI:EU:C:1981:48]. 
Asunto 182/78, Bestuur van het Algemeen Ziekenfonds Drenthe-Platteland contra G. Pierik, STJ 31 de mayo de 1979, [ECLI:EU:C:1979:142].

Asuntos acumulados 82/86 y 103/86, Giancarlo Laborero y Francesca Sabato contra Office de sécurité sociale d'outre-mer (OSSOM), STJ 9 de julio de 1987, [ECLI:EU:C:1987:356].

Asunto 300/84, A. J. M. Van Roosmal contra Bestuur van de Bedrijfsvereniging voor de Gezondheid, Geestelijke en Maatschappelijke Belangen, STJ 23 de octubre de 1986, [ECLI:EU:C:1986:402].

Asunto 153/91, Camille Petit v Office national des pensions, STJ 22 de septiembre de 1992, [ECLI:EU:C:1992:354].

Asunto 10/78, Tayeb Belbouab contra Bundesknappschaft, STJ 12 de octubre de 1978, [ECLI:EU:C:1978:181].

Asunto 442/16, Florea Gusa contra Minister for Social Protection y otros en contra del Ministro de Asuntos Sociales de Irlanda y otros, STJ 20 de diciembre de 2017, [ECLI:EU:C:2017:1004].

Asunto C-15/90, David Maxwell Middleburgh contra Chief Adjudication Officer, STJ 4 de octubre de 1991, [ECLI:EU:C:1991:377].

Asunto C-251/94, Eduardo Lafuente Nieto contra Instituto Nacional de la Seguridad Social (INSS) y Tesorería General de la Seguridad Social, STJ 12 de septiembre de 1996, [ECLI:EU:C:1996:319].

Asuntos acumulados C-31/96, C-32/96 y C-33/96, Antonio Naranjo Arjona contra Instituto Nacional de la Seguridad Social (INSS), Francisco Vicente Mateos contra Instituto Nacional de la Seguridad Social (INSS) y Tesorería General de la Seguridad Social (TGSS) e Instituto Nacional de la Seguridad Social (INSS) contra Laura García Lázaro, STJ 9 de octubre de 1997, [ECLI:EU:C:1997:475].

Asunto C-153/97, Aristóteles Grajera Rodríguez contra Instituto Nacional de la Seguridad Social (INSS) y Tesorería General de la Seguridad Social (TGSS), STJ 17 de diciembre de 1998. [ECLI:EU:C:1998:615].

Asunto C-282/11, Concepción Salgado González contra Instituto Nacional de la Seguridad Social (INSS) y Tesorería General de la Seguridad Social (TGSS), STJ 21 de febrero de 2013, [ECLI:EU:C:2013:86]. 


\title{
INTERVENCIÓN DEL TRIBUNAL DE JUSTICIA DE LA UNIÓN EUROPEA EN EL ÁMBITO DE COORDINACIÓN DE LOS SISTEMAS DE SEGURIDAD SOCIAL EUROPEOS
}

\section{Intervention of the court of justice of the European Union in the area of coordination of the european social security systems}

\author{
Verónica Lidia Martínez Martínez \\ Doctora en Derecho ${ }^{1}$ \\ Profesora-Investigadora de la Universidad Anáhuac (México) \\ marb_cap@hotmail.com
}

http://dx.doi.org/10.18543/ed-68(2)-2020pp169-204

\section{Copyright}

Estudios de Deusto es una revista de acceso abierto, lo que significa que es de libre acceso en su integridad. Se permite su lectura, la búsqueda, descarga, distribución y reutilización legal en cualquier tipo de soporte sólo para fines no comerciales, sin la previa autorización del editor o el autor, siempre que la obra original sea debidamente citada y cualquier cambio en el original esté claramente indicado

Estudios de Deusto is an Open Access journal which means that it is free for full access, reading, search, download, distribution, and lawful reuse in any medium only for non-commercial purposes, without prior permission from the Publisher or the author; provided the original work is properly cited and any changes to the original are clearly indicated. 